\title{
DETERMINACIÓN DEL CONCEPTO DE MEXICANISMO Y SU IDENTIFICACIÓN EN LOS DICCIONARIOS ACADÉMICOS
}

\author{
Pluralidad Terminológica PARA DenOMinar \\ LOS PARTICULARISMOS GEOGRÁFICOS
}

La pluralidad terminológica con que se designa la noción de 'peculiaridad o particularidad lingüística de un país o de una región determinada, con respecto a la lengua común, general o estándar', merece ser estudiada. Los términos globales de dialectalismo, localismo, provincialismo o regionalismo se han empleado en lingüística y en obras lexicográficas para referirse a esta noción, a veces, como sinónimos, pero también con matices que los especifican y diferencian. Lo mismo ha ocurrido con los términos significativamente más delimitados, desde la perspectiva geográfica, de americanismo (designación general) o de mexicanismo, chilenismo, argentinismo, etc. (designaciones particulares).

Con la finalidad de precisar el concepto de mexicanismo en los párrafos que siguen, reviso esta pluralidad terminológica en el material que ofrece la tradición lexicográfica hispánica, particularmente los diccionarios académicos, y las aportaciones, en este rubro, de algunos lingüistas.

Provincialismo y voz (vocablo, frase) provincial

Con el significado que aquí interesa, provincialismo se define por primera vez en ${ }_{10} D R A E 1852^{1}$, en la segunda acepción, como si se tratara de un plural: "Los modismos propios de cada

${ }^{1}$ Utilizo aquí la abreviatura $D R A E$ para referirme al diccionario académico, antecedida por un subíndice que indica el número de la edición, y seguida del año de su publicación. 
provincia”; definición muy similar, pero ya en singular, se halla en la edición siguiente, de 1869: "Cualquiera de los modismos propios de cada provincia”. Se modificó sin la mención de "modismo" desde la duodécima hasta la actual: "Voz o giro que únicamente tiene uso en una provincia o comarca de un país o nación" ( ${ }_{22}$ DRAE 2001).

En contraste, el vocablo provincial se registró en el cuerpo del diccionario desde el Diccionario de Autoridades (DA1726-39) ${ }^{2}$, marcado como adjetivo, pero definido como sustantivo en su sentido general: "Lo que toca o es perteneciente a alguna provincia"; esta definición, corregida y ofrecida como proposición adjetiva, se halla en ${ }_{12} D R A E$ 1884: "Perteneciente o relativo a una provincia", y así se ha conservado hasta el presente.

Provincial fue utilizado, además, en la "Explicación de abreviaturas", desde la segunda edición del $D A$ de 1770, como: "Provinc... Voz o frase provincial" (p. lxii), para referirse a las distintas provincias del interior de España. Se conserva en frases como las siguientes: "Provincial de Andalucía", "Provincial de la Mancha" o "Provincial de Toledo", entre las abreviaturas desatadas desde los primeros repertorios del DRAE hasta la edición última del siglo xix $\left({ }_{13} D R A E 1899\right)^{3}$. Hay que resaltar que

${ }^{2}$ De hecho, en las informaciones que este diccionario nos ofrece sobre la variación espacial en la parte de los preliminares ("Prólogo", "Historia de la Real Academia Española”, etc.) se menciona exclusivamente provincia o provincial: "voz provincial", "voz peculiar y propia de alguna provincia y reino" -Abrevio este diccionario como $D A 1726-39$ y $\operatorname{como}_{2} D A 1770$ la segunda ed. del mismo, que sólo reunió las palabras que iniciaban con A y B.

${ }^{3}$ Además de las citadas se abrevian: Provincial de Aragón, Provincial de Asturias, Provincial de Asturias de Santillana, Provincial de Extremadura, Provincial de Galicia, Provincial de Granada, Provincial de Murcia, Provincial de Navarra, Provincial de Rioja (DRAE 1780); éstas más las siguientes: Provincial de las Montañas, Provincial de las Montañas de Burgos en ${ }_{2} D R A E$ 1783. En la quinta ed. $\left.{ }_{5} D R A E 1817\right)$ y en la siguiente se elimina Provincial de Granada, conservándose las otras trece abreviaturas, pero se anexa nuevamente en la séptima ed. (글 $D A E 1817)$. El siguiente cambio ocurre en ${ }_{11} D R A E 1869$, con el añadido de Provincial de Navarra. Pero se altera notablemente en la duodécima ed. $\left({ }_{12} D R A E 1884\right)$ que incluye 34 abreviaturas: Provincial de Andalucía, Provincial de Aragón, Provincial de Asturias, Provincial de Badajoz, Provincial de Baleares, Provincial de Burgos, Provincial de Cádiz, Provincial de Canarias, Provincial de Castilla, Provincial de Cataluña, Provincial de Córdoba, Provincial de Extremadura, Provincial de Galicia, Provincial de Granada, Provincial de Filipinas, Provincial de León, Provincial de Málaga, Provincial de Mallorca, Provincial de la Mancha, Provincial de Murcia, Provincial de Navarra, Provincial de Rioja, Provincial de Salamanca, Provincial de Santander, Provincial de Segovia, 
durante la época colonial los territorios hispanoamericanos no fueron mencionados de esta forma. Se explicitan únicamente "Antillas" y "Cuba" en las dos últimas ediciones de ese siglo, por ser Cuba, Puerto Rico y Santo Domingo las últimas posesiones españolas en América.

Ahora bien, aunque no se calificaron expresamente como "provinciales" o como "provincialismos" las peculiaridades lingüísticas de las diversas colonias americanas, salvo los casos ya citados de "Cuba" y "Antillas", y mucho menos aún cuando lograron su independencia, llama la atención que tanto provincialismo como voz provincial se generalizaran formando parte de los títulos de distintos tipos de repertorios lexicográficos entre los siglos XVIII y xx. Y justamente, así se incluyó el plural de este segundo término en el texto del siglo XviII considerado el primer repertorio de americanismos, el Vocabulario de voces provinciales de la América usado en el Diccionario geográfico-histórico de ella y de los nombres propios de plantas y animales (VPAMER1789), que apareció como apéndice al Diccionario geográfico-histórico de las Indias occidentales de Antonio de Alcedo, el que se justifica por referirse a las colonias hispanoamericanas de aquella época.

Durante el siglo xıx y parte del xx, provincialismo alcanzó mayor auge que su sinónimo - voz provincial- en los títulos de muchas obras lexicográficas de regionalismos, en España y en Hispanoamérica ${ }^{4}$, y de artículos sobre los mis-

Provincial de Sevilla, Provincial de Teruel, Provincial de Toledo, Provincial de Valencia, Provincial de Vizcaya, Provincial de Zamora, Provincial de Zaragoza. Además, las siguientes dos, que resalto por tratarse de referencias a Hispanoamérica: Provincial de Antillas y Provincial de Cuba. En ${ }_{13} D R A E$ 1899 fueron agregadas cuatro más: Provincial de Almería, Provincial de Ávila, Provincial de Palencia, y Provincial de Soria.

${ }^{4}$ Entre las obras lexicográficas relacionadas con México puedo mencionar las siguientes, casi todas del siglo $\mathrm{xx}$, en las que los vocablos que reviso se refieren generalmente a particularismos de regiones o estados de México, aunque hay algunos que parecen referirse a los que serían actualmente mexicanismos diferenciales de uso general en nuestro país: EDMUNDo BoLIo Ontiveros, Mayismos, barbarismos y provincialismos yucatecos, Imprenta El Porvenir, Mérida, 1931; SAlvador Cordero, Barbarismos, galicismos y solecismos de uso más frecuente; manera de evitarlos conforme a los cánones establecidos por los buenos hablistas, con un apéndice de los principales modismos, refranes y provincialismos de empleo corriente en la República Mexicana, así como una pequeña relación de las principales reglas ortográficas, Librería de la Vda. de C. Bouret, Paris, 1918; Aurelio de LEón, Barbarismos comunes en México; solecismos, anglicismos, provincialismos del norte, voces forenses impropias, Imprenta Mundial, México, 1936-37; 
$\operatorname{mos}^{5}$. Lapesa ha explicado la popularidad que alcanzaron estas voces a partir del éxito que tuvo el Diccionario provincial casi razonado de voces cubanas de Esteban Pichardo, publicado cuando Cuba era aún "provincia española" 6 . Supongo, por otro lado, que los autores de estos trabajos decidieron describir el léxico de sus regiones natales o adoptivas ${ }^{7}$, ora con la intención de corregir "todos los barbarismos, solecismos i demás vicios que, de algún modo, quebrantan las leyes de la pureza i propiedad del bien decir"8, ora esperanzados en que la siguiente edición del diccionario académico los recogiera y así completar la información regional que proporcionaba, o por ambos motivos, generalmente sin cuestionar para nada la posición dominante del español de España. El desprestigio actual de ambos términos ${ }^{9}$ se podría deber a percibirlos como

Prudencio Patrón Peniche, Léxico yucateco, barbarismos, provincialismos y mayismos, Talleres Tipográficos Tenochtitlán, México, 1932; Félız Ramos I Duarte, Diccionario de mejicanismos. Colección de locuciones i frases viciosas. Con sus correspondientes críticas $i$ correcciones fundadas en autoridades de la lengua; máximas, refranes, provincialismos i remoques populares de todos los Estados de la República Mejicana, Imprenta de Eduardo Dublán, Méjico, 1895 (que abrevio DM1895); Francisco Javier Santamaría, Diccionario de mejicanismos; razonado comprobado con citas de autoridades, comparado con el de americanismos y con los vocabularios provinciales de los más distinguidos diccionaristas hispanoamericanos, Porrúa, México, 1959 y El provincialismo tabasqueño; ensayo de un vocabulario del lenguaje popular, comprobado con citas, comparado con el de mexicanismos y los de otros países hispanoamericanos, Botas e Hijos, México, 1921. Lo mismo sucedió en otros países hispanoamericanos.

${ }^{5}$ También, relacionados únicamente con México, tenemos: JoAQUín García Icazbalceta, "Provincialismos mexicanos", Memorias de la Academia Mexicana, México, 1886, t. 3, pp. 170-190, 296-301, 426-432 y en su Vocabulario de mexicanismos, pp. v-xviii; NicolÁs León, "Glosario de voces castellanas derivadas del idioma tarasco o de Michoacán: contribución para el Diccionario de provincialismos”, Anales del Museo de Michoacán, 1 (1888), 97-104; Manuel G. Nevilla, "Provincialismos de expresión en Méjico”, Biblioteca de Dialectología Hispanoamericana, Buenos Aires, 1938, pp. 189-198 y "Provincialismos de expresión en Méjico. Cuáles son los aceptables y cuáles los viciosos”, Memorias de la Academia Mexicana de la Lengua, t. 6, pp. 352-367.

${ }^{6}$ Cf. Rafael Lapesa, "Sobre el concepto exclusivista del americanismo lingüístico; sus consecuencias en la lexicografía actual”, Homenaje a Humberto López Morales, Arcos/Libros, Madrid, 1992, pp. 35-39.

${ }^{7}$ Como fue el caso del cubano Félix Ramos y Duarte, autor del DM1895, o del dominicano Esteban Pichardo.

${ }^{8}$ DM1895, "Al público", p. 5.

${ }^{9}$ Tomás Buesa y José M. Enguita (Léxico del español de América: su elemento patrimonial e indígena, Mapfre, Madrid, 1992, p. 20) mencionan sólo provincialismo de los dos que trato, y barbarismo, al afirmar que "han quedado 
reflejo de la situación marginal o periférica de los países hispanoamericanos con respecto a España ${ }^{10}$, como lo manifiesta Ambrosio Rabanales al referirse a la posición de Juan Valera sobre los americanismos denominadores de realidades exclusivas de América: “"provincialismos' los llama también este autor, al igual que Batres, Membreño, Rivodó y otros, olvidándose de que los países de Hispanoamérica ya no son 'provincias' del Imperio Español"11.

$\mathrm{Al}$ parecer, el término provinciano se fue cargando de un matiz peyorativo en su uso coloquial ${ }^{12}$, aumentando de esta forma el desprestigio de provincialismo y provincial.

\section{Localismo y dialectalismo}

Julio Casares ${ }^{13}$ empleó los términos localismo y dialectalismo para designar dos clases de particularismos geográficos. Afirmó que los localismos

no forman parte del patrimonio lingüístico general porque no salvan las fronteras geográficas del ámbito en que viven y circulan. Muchas veces los vocablos, locuciones y giros que caracterizan estas hablas locales nacieron en el mismo territorio en que los hallamos, pero otras veces gozaron del favor general antes de quedar

prácticamente arrumbadas en la actualidad”. Más precisos son los comentarios de José G. Moreno de Alba ("La provincia, el interior", Minucias del lenguaje, F.C.E., México, 1992, pp. 246-247) sobre el valor de provincia y provinciano en México.

${ }^{10} \mathrm{Y}$ que, en el terreno lingüístico hispanoamericano se manifestó al presentar las variedades hispanoamericanas, como muy poco prestigiosas en relación con el español de España, en especial por confrontar el español popular de América con el español ejemplar de España, o mejor dicho, con la norma académica, es decir, con lo que se hallaba consignado en la Gramática y en el Diccionario.

${ }^{11}$ A. Rabanales, Introducción al estudio del español de Chile, Instituto de Filología de la Universidad de Chile, Santiago, 1953, p. 26.

${ }^{12}$ Moreno de Alba escribe: "Nótese de paso asimismo el innegable sentido peyorativo que, muy frecuentemente, acompaña al término provinciano referido a personas" (op. cit., p. 246) y el Diccionario de lingüística de Enrigue Fontanillo (Rei, México, 1991 [1986]): "Elemento lingüístico, construcción, giro, vocablo, etc., propio de una provincia determinada. A menudo se emplea en el sentido despectivo de "provinciano»" (provincialismo; las cursivas son mías).

${ }^{13}$ Julio Casares, Introducción a la lexicografía moderna, $3^{\mathrm{a}}$ ed., CSIC, Madrid, 1992 [1950]. 
recluidos en áreas más o menos extensas. A estos particularismos geográficos los llamaremos en lo sucesivo "localismos"... tanto si su difusión sólo alcanza a una feligresía rural como si abarca regiones más dilatadas y aun provincias o naciones enteras (p. 294) ${ }^{14}$.

En cambio, los dialectalismos ${ }^{15}$ son los particularismos geográficos que, según Casares (op. cit., p. 308) contradicen las regularidades fonéticas y morfológicas de la lengua común ${ }^{16}$. Con estas dos designaciones, nuestro lexicógrafo trataba de distinguir entre los localismos, particularismos surgidos de la lengua común española, es decir, los particularismos geográficos procedentes de los dialectos secundarios ${ }^{17}$ o consecutivos ${ }^{18}$ (andaluz,

${ }^{14}$ Lázaro Carreter en su Diccionario de términos filológicos ( $3^{\mathrm{a}} \mathrm{ed}$., Gredos, Madrid, 1984, que abrevio, a partir de aquí, DTF) toma otra cita de esta misma obra para redactar su definición de localismo y distinguirlo de dialectalismo: "Peculiaridad lingüística, propia de una localidad, diferente del dialectalismo. «Los localismos son formas que se apartan de la lengua común, pero que en ningún caso contradicen las leyes por que se rige dicha lengua en cuanto a fonética, derivación, desinencias, flexiones y prosodia; mientras que las variantes dialectales obedecen a normas divergentes, que son precisamente las que individualizan el dialecto respectivo y permiten circunscribir su ámbito. Tal vez en algún caso concreto no sea fácil determinar si se trata de un localismo puro o si va acompañado de un matiz dialectal» (J. Casares)" (s.v. localismo).

${ }^{15}$ Curiosamente, Lázaro Carreter en su DTF no mantiene la diferencia que sostuvo Casares bajo dialectalismo, al que define como "rasgo lingüístico perteneciente a un dialecto" y remite a provincialismo, en cuyo artículo consigna dos acepciones: "1. Rasgo de una lengua que subsiste o finca en una provincia, cuando en el resto del territorio no se usa. 2. Dialectalismo, sobre todo referido a una amplia provincia y empleado por los hablantes sin voluntad diferencial".

${ }^{16}$ Es decir, son los vocablos procedentes de los que Casares denomina dialectos: "Muy distinto es el caso en lo tocante, por ejemplo, al bable, al gallego o al catalán. Aquí se trata de verdaderos lenguajes, es decir, de mecanismos lingüísticos sui generis, que morfológica y fonéticamente han seguido una evolución a todas luces diferente de la que siguió el castellano. Estos dialectos estarían fuera de lugar en un diccionario de la lengua que llamamos por antonomasia «española»" (op. cit., p. 309).

${ }^{17}$ Para Eugenio Coseriu ("Los conceptos de 'dialecto', 'nivel' y 'estilo de lengua', y el sentido propio de la dialectología”, $L E A, 3,1981,1-32$ ), los dialectos secundarios "serían los formados dentro de una lengua histórica común” (p. 14), a los que se les suele denominar 'formas regionales de la lengua'. Véase también Eugenio Coseriu, "El español de América y la unidad del idioma”, I Simposio de Filología Iberoamericana (Sevilla, 26 al 30 de marzo de 1990), Libros Pórtico, Zaragoza, 1990, pp. 43-75, esp. p. 57.

18 "Variante regional de una lengua resultante de la evolución general de ésta en un periodo y espacio determinados; p. ej. el andaluz es, con respec- 
canario y los de las distintas naciones o regiones hispanoamericanas), y los dialectalismos, particularismos geográficos procedentes de los dialectos primarios ${ }^{19}$ o constitutivos ${ }^{20}$ (el astur-leonés o el navarro-aragonés). Sin embargo, Casares reconoce que puede haber dificultades de identificación en ciertos casos concretos.

Esta distinción no ha sido general ni se ha mantenido hasta nuestros días, seguramente porque predomina asociar localismo a una superficie geográfica poco extensa, mientras que dialectalismo se relaciona, por medio del adjetivo dialectal, con dialecto, como se puede comprobar al revisar la sucesión de definiciones de estos términos en el DRAE a partir del primer registro de ambos en la décimo sexta edición ( ${ }_{16} D R A E$ 1936).

Localismo se define en la segunda acepción como: "Vocablo o locución que sólo tiene uso en determinada localidad", y se conserva de idéntica forma en las dos ediciones subsecuentes ${ }_{17} D R A E 1947$ y ${ }_{18} D R A E 1956$. Se incluye como tercera acepción, con ciertas modificaciones en la ${ }_{19} D R A E$ 1970: "Vocablo o locución que sólo tiene uso en un área distinguida", redacción en la que es evidente la errata "distinguida" por "restringida", como se puede comprobar en la siguiente edición en que aparece ya corregida $^{21}$, y que se mantiene casi idéntica, aunque como cuarta, en las ediciones más recientes y con otro yerro: "Vocablo o locución que sólo tiene uso en una área restringida" 22 ( ${ }_{21} D R A E$ 1992 y $\left._{22} D R A E 2001\right)$. Y con esta interpretación significativa se emplea actualmente.

to al castellano, dialecto consecutivo del español" (ENRIQUE FontANillo, Diccionario de lingüistica, s.v. dialecto).

${ }^{19}$ E. Coseriu indica que los dialectos primarios están conformados por "los dialectos más antiguos que la lengua común (incluido el dialecto del cual ésta procede), así como los dialectos de las lenguas históricas carentes de forma común” y precisa que a éstos se les suele llamar 'dialectos' sin ningún tipo de precisión. Para mayores detalles de la distinción entre dialectos primarios y secundarios, e incluso entre éstos y los terciarios de la lengua española: "Los conceptos de ' dialecto'...”, p. 14. Cf. también Coseriu, "El español de América y...”, pp. 165-166.

20 "Variante regional de una lengua, coetánea con ésta, que por razones históricas no ha alcanzado el mismo grado de estandarización o de reconocimiento oficial; p. ej. en el español, el aragonés o el leonés con respecto al castellano" (Fontanillo, DL, s.v. dialecto).

21 "Vocablo o locución que sólo tiene uso en un área restringida" $\left({ }_{20} D R A E\right.$ 1984, s.v.).

${ }^{22}$ Las cursivas son mías y resaltan la última modificación, que supongo error, ya que ante los femeninos que empiezan con $a$ tónica se utilizan los artículos definidos e indefinidos masculinos. 
Dialectalismo se registra con dos acepciones: "Voz o giro dialectal. || 2. Carácter dialectal” ( $\left.{ }_{16} D R A E 1936\right)$. La primera, que es la que nos interesa, se ha mantenido intacta en las subsecuentes ediciones académicas, incluida la más reciente ${ }^{23}$. No lo recogen Enrique Alcaraz ni M. Antonia Martínez Linares, autores del $D L M^{24}$, a pesar de que a dialecto y dialectología les dedican un artículo extenso, pero sí el de Fontanillo:

Rasgo lingüístico, fonológico, morfológico, sintáctico, léxico, etc. propio o procedente de un dialecto, que se incorpora esporádica o permanentemente a la lengua común; p. ej. el andalucismo juerga, el argentinismo pibe (Diccionario de lingüistica).

El vocablo dialecto ${ }^{25}$, a la inversa de su derivado, formó parte de la nomenclatura desde el primer diccionario académico

${ }^{23}$ Sólo en la tercera ed. del Diccionario manual e Ilustrado de la Lengua Española $\left({ }_{3} D M I L E 1983\right)$ se enmendó este vocablo, como: "Préstamo procedente de un dialecto que se incorpora a la lengua general".

${ }^{24}$ Abrevio de esta forma su Diccionario de lingüistica moderna, Ariel, Barcelona, 1997.

${ }^{25}$ De acuerdo con Coseriu ("Los conceptos de 'dialecto'...”, pp. 5-11), este término conlleva el significado etimológico "modo de hablar" o "sistema lingüístico inmediatamente realizable en el hablar" con una "relación de subordinación a una lengua histórica", significado que se complementó, desde la antigüedad griega, con el rasgo de "delimitación en el espacio" y de esta manera designa el "modo de hablar propio de un lugar". Este término, como podemos observar, estuvo asociado en su origen a la perspectiva geolingüística -aunque llegó además a manifestar estilos, como se comprueba en la existencia de los dialectos que caracterizaron los distintos géneros de la literatura griega. Sin embargo, este rasgo de delimitación espacial, aunque se conserva aún en el ámbito de la dialectología y de algunas otras disciplinas lingüísticas, ha ido perdiendo terreno sobre todo a partir del empleo de dialecto en algunos estudios sociolingüísticos para referirse a los sociolectos o variedades sociales. Creo que esto explica el uso de denominaciones sinonímicas tales como dialecto geográfico, dialecto territorial o geolecto, que se distinguen de dialecto social o sociolecto. Max Figueroa Esteva ("La variación como diversidad de normas lingüísticas. Notas para un acercamiento preliminar", en Varia lingüistica y literaria. 50 años del CELL, t. 1: Lingüistica, eds. R. Barriga Villanueva y P. Martín Butragueño, El Colegio de México, México, 1997, p. 422) ejemplifica estos usos y este problema: "Actualmente, el término dialecto tiende cada vez más a ser tratado como hiperónimo de (al menos) dos cohipónimos igualmente fundamentales: geolecto y sociolecto. También el término dialectología -que, lo mismo que dialecto, se asoció inicialmente sólo a la perspectiva geolingüística- ha empezado a tratarse como hiperónimo de (al menos), dos cohipónimos igualmente fundamentales: geolingüística (dialectología territorial) y sociolingüistica (dialectología social)”. 
(DA 1726-39). En él y hasta la sexta edición del usual, la definición que se ofrece identifica dialecto con idioma ${ }^{26}$. Se modifica ésta, a partir de ${ }_{7} D R A E 1832$, a: "Lenguaje que tiene con otro u otros un origen común, aunque se diferencie en las desinencias o en otras circunstancias de sintaxis, pronunciación, etc.", y que persistirá hasta ${ }_{11} D R A E 1869$.

En la duodécima edición $\left({ }_{12} D R A E 1884\right)$ se plasman dos acepciones muy similares del vocablo que nos ocupa, la primera muy cercana a la consignada anteriormente: "Lenguaje que, sin ser realmente diverso de otro u otros, difiere de ellos en algunos accidentes analógicos y sintácticos, y con especialidad en lo que atañe a los sonidos"; y la segunda, con la explicitación del aspecto geográfico o territorial que lo caracteriza: "Cada uno de los lenguajes particulares de esta índole que se hablan en determinados territorios de una nación, a diferencia de la lengua general, oficial y literaria del mismo país" ${ }^{27}$. Estas acepciones se reunirán en una sola:

Cada una de las variedades de un idioma, que tienen cierto número de accidentes analógicos y sintácticos propios, y más comúnmente las que se usan en determinados territorios de una nación, a diferencia de la lengua general y literaria $\left({ }_{13} D R A E\right.$ 1899 y $\left.{ }_{14} D R A E 1914\right)$,

para reaparecer en dos a partir de la décima quinta $\left({ }_{15} D R A E 1925\right)$ en donde la primera se refiere a los dialectos secundarios o consecutivos: "Cada una de las variedades de un idioma, que tienen cierto número de accidentes propios, y más comúnmente las que se usan en determinados territorios de una nación, a diferencia de la lengua general y literaria”, y la segunda, a los dialectos primarios o constitutivos, informando además que su uso está restringido al ámbito de la lingüística: "2. En lingüística, cualquier lengua en cuanto se la considera con relación al grupo de las varias derivadas de un tronco común. El español es uno de los DIALECTOS nacidos del latín".

Este artículo se perfecciona en la primera edición del Diccionario manual e ilustrado de la lengua española (DMILE1927) al ofrecerlo con un ejemplo para la primera acepción, "el DIALECTO murciano”. Las dos acepciones, cada una con sus res-

26 "Idioma, propiedad de cada lengua en sus voces, explicación y pronunciación” ( $\left.{ }_{5} D R A E 1817\right)$.

${ }^{27}$ Las cursivas son mías. 
pectivos ejemplos, se conservarán, con pequeñas variantes en la definición, desde ${ }_{16} D R A E 1936$ hasta ${ }_{19} D R A E 1970$.

La tercera edición de la versión manual ( $\left.{ }_{3} D M I L E 1983 b\right)$ reordena y precisa las acepciones, y añade una tercera. Este artículo se conserva casi de la misma forma en las siguientes dos ediciones del DRAE (1984 y 1992), aunque sin el ejemplo referido al "dialecto murciano", y se perfecciona en la más reciente:

Ling. Sistema lingüístico considerado con relación al grupo de los varios derivados de un tronco común. El español es uno de los DIALECTOS nacidos del latín. || 2. Ling. Sistema lingüístico derivado de otro, normalmente con una concreta limitación geográfica, pero sin diferenciación suficiente frente a otros de origen común. || 3. Ling. Estructura lingüística, simultánea a otra, que no alcanza la categoría social de lengua ${ }_{22} D R A E 2001$, s.v.).

El $D L M$ (s.v. dialecto, dialectología) reúne distintas nociones de dialecto, desde la empleada por los neogramáticos hasta las más actuales. Estas últimas aluden a tres definiciones: las "variedades de grandes comunidades de habla, como el inglés británico, el inglés australiano, etc." que se denominan dialectos geográficos o macrodialectos; "las variedades de comunidades de habla más pequeñas, que existen dentro de los grandes dialectos geográficos", a las que se reconoce con el nombre de dialectos regionales o microdialectos y, por último, la correspondiente a los dialectos sociales.

Ahora bien, todas estas explicaciones de dialecto ofrecen un denominador común: se trata de una variedad interna de la lengua, en concreto de la geográfica, cuya descripción abarca su homogeneidad y su diversidad con respecto a las otras variedades geográficas de la misma lengua. Yjustamente, los dialectalismos constituyen los hechos lingüísticos que caracterizan sólo la diversidad, la especificidad o la peculiaridad de los dialectos.

Por otra parte, la distinción referida a los macrodialectos y microdialectos podría servir para diferenciar dos tipos de dialectalismos, los macrodialectalismos que corresponderían a las peculiaridades generales de un país con respecto a una lengua común a varios países, y los microdialectalismos que designarían los específicos de determinadas zonas dentro de un país con respecto al uso general o común en dicho país. De esta forma los "mexicanismos" peculiares a todo México vendrían a constituir los macrodialectalismos mexicanos o macromexicanismos, mientras 
que los dialectalismos propios del español mexicano yucateco o sonorense integrarían el grupo de los microdialectalismos mexicanos o micromexicanismos.

\section{Regionalismo}

Aunque como entrada regionalismo se encuentra en el DRAE desde la última edición del siglo $\mathrm{XIX}^{28}$, el significado que me interesa no se registra sino hasta la décimo octava $\left({ }_{18} D R A E 1956\right)$, manteniéndose sin variación, como tercera acepción, desde entonces hasta la edición más actual ${ }_{22} D R A E$ 2001): "Vocablo o giro privativo de una región determinada".

Este término se ha registrado en varios diccionarios de lingüística. En el $D L M$ se lee:

La 'región' es la zona o porción de territorio determinada por caracteres lingüísticos, étnicos, climatológicos, etc., diferentes. Los vocablos o giros privativos de una región se llaman regionalismos, los cuales marcan la procedencia de una zona pero no constituyen una VARIEDAD lingüística como los DIALECTOS ${ }^{29}$.

Y el Fontanillo $(D L)$ ofrece, bajo regionalismo:

Palabra, giro o construcción característica de una determinada región o territorio. Se distingue del ruralismo en que puede comprenderlo junto con formas propiamente urbanas, pero como él suele quedar al margen de los modelos de la lengua considerados formales; p. ej. extremeño jurdano mollinear, lloviznar; canario losotros, nosotros.

Por otra parte, José Pedro Rona selecciona regionalismo para designar cualquier particularismo geográfico sin concreción de su ubicación, en su célebre artículo "¿Qué es un americanismo?"30, donde lo define como "todo hecho de len-

${ }^{28}$ Definida como "Tendencia o doctrina política según las cuales en el gobierno de un estado debe atenderse especialmente al modo de ser y a las aspiraciones de cada región. || Amor o apego a determinada región de un estado y a las cosas pertenecientes a ella" (${ }_{13} D R A E 1899$, s.v.).

${ }^{29}$ Segunda acepción del artículo región, regionalismo.

${ }^{30}$ En El Simposio de México. Enero de 1968. Actas, informes y comunicaciones, México, 1969, pp. 135-148. El objetivo de este artículo se explicita desde el primer párrafo: "Se trata de decidir, en general, qué se debe entender por 
guaje cuya ocurrencia difiere entre una región y otra" (p. 137), sobreentendiéndose que se trata de regiones que poseen una misma lengua histórica.

En definitiva, se puede concluir que este vocablo vino a sustituir el de provincialismo o el de voz (término, vocablo, etc.) provincial.

\section{Americanismo}

Esta palabra aparece en la nomenclatura del diccionario académico por primera vez en ${ }_{12} D R A E 1884^{31}$. Fue explicitada como: "Vocablo o giro propio o privativo de los americanos que hablan la lengua española”. Esta definición se altera muy poco en ${ }_{16} D R A E$ 1936: "Vocablo o giro propio o privativo de los americanos, y particularmente de los que hablan la lengua española", y da lugar, a partir del suplemento de ${ }_{19} D R A E 1970$, a las siguientes dos acepciones, que permanecen inalteradas hasta la edición de 2001:

Vocablo, giro, rasgo fonético, gramatical o semántico que pertenece a alguna lengua indígena de América o proviene de ella. \| 6. Vocablo, giro, rasgo fonético, gramatical o semántico peculiar o procedente del español hablado en algún país de América ( ${ }_{22} D R A E 2001$, s.v.).

Rona cuestiona estas definiciones al señalar que "se ha abusado muchísimo del término americanismo, incluso en obras muy serias, y aun en el Diccionario de la Real Academia Española"32

regionalismo, y, en particular, por americanismo" (p. 135), precisando de esta forma las conclusiones de A. Rabanales, primer lingüista en estudiar sistemáticamente el problema de la determinación del concepto de americanismo (cf. op. cit.).

${ }^{31}$ J.P. Rona, “¿Qué es un americanismo?”, p. 145.

${ }^{32}$ La misma ed. que introduce, consecuentemente, Amér [ica] como marca restrictiva geolectal en su "Explicación de abreviaturas"; sin embargo ya la había empleado en ediciones anteriores desde el ${ }_{2} D A 1770$, aunque no resulta claro si para indicar la procedencia de la voz, su uso diferencial o ambos. En la siguiente ed. de 1914 se añadió Amér[ica] Merid[idional] y en ${ }_{15} D R A E$ 1925, Amér [ica] Central, que se conservan hasta el repertorio más reciente. Sólo la penúltima ed. ( $\left.{ }_{21} D R A E 1992\right)$ no incluyó entre las abreviaturas la de Amér[ica] Central, que sí se utiliza en los artículos lexicográficos. Tanto en el cuerpo de este repertorio, como en su versión en CD, se matizaron excesivamente las marcas diatópicas al anexar las que correspondían a: 
debido, según explica, a haberlo identificado con "regionalismo de cierta parte de América" ( $i d$. .). Y agrega: "Y la Academia llama 'americanismos' a muchos términos que en realidad, sólo se usan en México o solamente en Chile" (id.). Ilustra esta interpretación cuando la aplica al español de España y denomina

"españolismo" o "peninsularismo" a todo vocablo, giro, rasgo fonético, gramatical o semántico peculiar o procedente del español hablado en algún lugar de España. Con lo cual el llamado "español de España" podría ser definido mediante vocablos o giros de algún bable local de Asturias o de algún hablar de una aldea andaluza. Sin embargo, creemos que lo que es peculiar o procedente de Asturias es simplemente un "asturianismo", y si lo es de Andalucía, es un "andalucismo". Del mismo modo, lo peculiar o procedente de México no pasa de ser un "mexicanismo", y si lo es de Chile, es un "chilenismo" (pp. 145-146, n. 9).

Hay que reconocer que este estudioso tiene razón cuando, al referirse a los mexicanismos o a los chilenismos, señala que "son americanismos sólo en cierto sentido, en cuanto se usan en América. No lo son en cuanto no son característicos del español americano" (id.; las cursivas son mías). Creo, coincidiendo con Rona, que en forma similar se podría aplicar esto mismo al llamado "español de España" y afirmar que los asturianismos, andalucismos o extremeñismos serían "españolismos" por usarse "en España", aunque no sean verdaderamente característicos de la totalidad del español de ese país. Sin embargo, esto no ha ocurrido porque no se ha tenido conciencia de que pudiera haber un español común entre los hispanohablantes españoles, y pienso que son los españoles, concretamente, los que más han padecido esta falta de conciencia, y así se ha confundido el español común de España con el español general o común a los hispanohablantes de las dos orillas del Atlántico, como muestra la tradición lexicográfica española de la RAE.

Rona afirma que no se encuentran "americanismos" stricto sensu ${ }^{33}$, es decir, ejemplos de rasgos lingüísticos, fonéticos, gramaticales, semánticos o léxicos, que abarquen toda Hispano-

América Central excepto Costa Rica, América Central menos Nicaragua y América del Sur, esta última para caracterizar únicamente yacaré, ya que el resto de casos similares llevaban la indicación de América Meridional.

${ }^{33}$ La distinción entre regionalismos stricto sensu, cuya difusión geográfica no trasciende los límites del territorio originario, y lato sensu, cuya difusión sí traspasa estos límites, se la debemos a Rabanales, op. cit., pp. 15-16. 
américa y nada más que esta zona ${ }^{34}$. Tampoco justifica utilizar "español americano" o "español de América" como denominación de un sistema o modalidad de la lengua unitaria y distinta del español empleado en España porque no existe. De hecho, lo que asienta en forma muy rotunda es que Hispanoamérica se caracteriza por su diversidad lingüística, coincidiendo con la visión de la mayoría de los estudiosos del "español americano"35. No obstante, se puede seguir hablando de americanismo, y aun de español de América, mientras hagamos una interpretación menos estricta de dichos términos, como han sugerido muchos lingüistas ${ }^{36}$. El mismo Rona había utilizado americanismo en sentido amplio, en trabajos anteriores ${ }^{37}$.

${ }^{34}$ De acuerdo con esta interpretación, no habría diccionarios de "americanismos". Los que se han denominado así, no reúnen "americanismos" en este sentido; se limitan a recoger regionalismos empleados en cada una de las naciones que integran Hispanoamérica, los de zonas que pueden trascender las fronteras políticas de uno o varios países -la del Río de la Plata, por ejemplo- o los de zonas más restringidas -como el español yucateco-, sin considerar que incluyen también los "diacrónicos", en la terminología de Rona, o "histórico genéticos”, en la de José JoaQuín Montes Giraldo (cf. infra, pp. 530-531).

${ }^{35}$ Entre ellos, JuAn M. Lope Blanch, quien ha insistido en señalar el "gigantesco mosaico dialectal" que conforman las diversas modalidades del español americano. También ha reafirmado la inexistencia del "español de América": "En efecto, pensar en la existencia de una norma lingüística hispanoamericana sería tanto como seguir pensando en la existencia de un español de América, esto es, de una modalidad lingüística básicamente homogénea y uniforme en todo el amplio territorio americano de la lengua española. Lo cual, si sostenido por algunos... como Alonso Zamora Vicente, por ejemplo, es hoy rechazado por quienes han estudiado desapasionadamente ese supuesto español de América. Hablar de «el» español de América resulta tan impropio e inexacto como hablar de «el» español de España... De tal manera que es hoy ya idea generalizada la de que esa supuesta unidad $u$ homogeneidad del español americano es tan solo un mito. Seguir hablando de «el español de América» es únicamente admisible como fórmula caprichosa - pero cómoda, por breve- designadora del conjunto de modalidades lingüísticas habladas en el Nuevo Mundo. Es designación que tiene sólo validez geográfica -e histórica-, pero de ninguna manera lingüística” (cf.J.M. LoPE BLANCH, La lengua española y sus problemas, UNAM, México, 1997, pp. 75-76).

${ }^{36}$ Así, también, Montes Giraldo, quien menciona que podría dudarse "de la conveniencia de este excesivo rigor terminológico" y sostiene que casos como el del voseo, "ausente en España y presente con diversa extensión e intensidad de uso casi en todos los países americanos, y en todo caso en lugares de las tres Américas, bien pueden llamarse americanismos" (Dialectología general e hispanoamericana. Orientación teórica, metodológica y bibliográfica, $3^{\mathrm{a}}$ ed., Instituto Caro y Cuervo, Santafé de Bogotá, 1995, p. 154).

${ }^{37}$ José Pedro Rona, "El problema de la división del español americano en zonas dialectales", en Presente y futuro de la lengua española. Actas de la 
El problema de la identificación de los regionalismos en las obras lexicográficas, especialmente en los repertorios de determinados "americanismos", fue la motivación esencial que condujo a Rabanales a plantear la dificultad de la definición de americanismo, o de chilenismo, y a elaborar una clasificación de regionalismos a partir de distintos criterios de definición ${ }^{38}$, para concluir que el único válido como americanismo es el criterio de origen:

Entendemos por chilenismo toda expresión oral, escrita o somatolálica originada en Chile desde cualquier punto de vista gramatical, por los chilenos que hablan el español como lengua propia o por los extranjeros residentes que han asimilado el español de Chile (op. cit., p. 31).

Rona, por su parte, afina teóricamente lo expuesto por Rabanales, señalando que sólo después de haber establecido la definición de regionalismo se puede llevar a cabo su clasificación, según los criterios que el lingüista decida aplicar ${ }^{39}$. Ilustra esto con la distinción entre los regionalismos sincrónicos y los diacrónicos, de acuerdo con el eje temporal del diasistema, y con la de regionalismos fonéticos, morfológicos, sintácticos y léxicos, según la naturaleza del hecho lingüístico.

Asamblea de Filología del I Congreso de Instituciones Hispánicas, Madrid, 1964, t. 1, pp. 215-226. Tomás Buesa y José María Enguita (Léxico del español de América, p. 22) mencionan esto y, además, cito: "el mismo J. P. Rona (1973: pp. 283-284) sugería que oponer un español americano al español de España es legítimo si se intenta la explicación de los factores que han intervenido en la formación de las nuevas modalidades o del vínculo que existe entre éstas y el lenguaje común peninsular”. El artículo de 1973 que señalan es: "Desarrollo de la lingüística y la filología en la América Latina", en Actas de la Primera reunión latinoamericana de lingüistica y filología, Viña del Mar, 1964, publicado nueve años después, es decir en 1973, en Bogotá, pp. 269-292.

${ }^{38}$ RABANALES estableció estos criterios en función de su origen americano (pp. 29-30) y de los siguientes usos: su uso privativo o peculiar (op. cit., pp. 7-12); su uso en relación con la extensión territorial americana abarcada -stricto y lato sensu- (pp. 13-21); su uso en relación con el prestigio sociocultural de quienes lo emplean (pp. 22-25) y, por último, su uso condicionado por la existencia de sinónimos en otros territorios (pp. 26-28).

39 "Si entendemos la definición como la reunión de los atributos esenciales del definido, el único criterio concebible para definir el regionalismo es el rasgo diatopía. Cualquier otro que se agregue al atributo esencial 'diferencia en el espacio', bien la sincronía, la diacronía, un nivel concreto de análisis, etc., servirá para clasificar regionalismo pero no para definirlo" (RonA, “¿Qué es un americanismo?”, p. 137). 
Los dos puntos de vista de estos lingüistas hay que tomarlos en cuenta para revisar las clases de dialectalismos de América que diferenciaron. Así, además de los americanismos de origen - origen homogeográfico ${ }^{40}$-, o regionalismos diacrónicos ${ }^{41}$, los dos autores coinciden en reconocer los regionalismos de uso privativo en un país, sin que trasciendan sus fronteras ${ }^{42}$, a los que Rona (p. 137) denominó sincrónicos. Este tipo de americanismos parecería implicar la existencia de un sinónimo o equivalente en otro dialecto; no obstante, Rabanales niega validez a la necesidad de la sinonimia, y de esta manera fundamenta el origen como único criterio pertinente:

[la sinonimia] en ningún caso ayuda a determinar el concepto de americanismo, pues si una voz se ha originado en América, con tener muchas voces "hermanas" o españolas como equivalentes, o no tener ninguna, no se altera su índole de voz americana (op. cit., p. 27).

Hay coincidencia entre estos autores, además, en que el rasgo stricto sensu de los regionalismos -requisito de la diatopía para Rona- puede darse en forma simultánea con otro rasgo ${ }^{43}$. En la perspectiva diasistemática de Rona correspondería a otros ejes y de esta manera se hallan: regionalismos "diatópicosinstráticos", "diatópico-diastráticos" e, incluso, "regionalismos diatópico-diafásicos, cuando el término existe en ambas regiones, pero pertenecen a distintos estilos de lengua. Así, una palabra puede ser coloquial en España y solemne en Uruguay"4.

${ }^{40}$ RABANALES, op. cit., pp. 29-30.

${ }^{41}$ Rona, “¿Qué es un americanismo?”, pp. 136-137.

${ }^{42}$ Rabanales, op. cit., pp. 7-14.

${ }^{43}$ RABANALEs lo señala de esta forma: "De acuerdo con ello [la diferencia específica de las definiciones de los diversos americanismos], podemos reunir las diversas definiciones en cinco grupos bien distintos, aun cuando haya algunas en que se consideran más de una de esas diferencias simultáneamente" (p. 5).

${ }^{44}$ Rona, p. 145. Raúl Ávila ha descrito estas correspondencias al determinar varios tipos de relaciones que resultan de contrastar dos modalidades o subsistemas diatópicos, centrado en los "subsistemas léxico-semánticos" de cada modalidad, cuando se consideran las relaciones internas y externas, connotativas y denotativas. Ofrece, para cada tipo, una fórmula en la que se señalan las relaciones internas y externas en cada modalidad (cf. "Variación léxica: connotación, denotación, autorregulación”, ALM, 35, 1997, 79-102, donde compara las ciudades de México y de La Habana y, del mismo Ávila, "Españolismos y mexicanismos: hacia un diccionario internacional de la 
A los dos criterios, fundados en el origen y en la diferenciación sincrónica, José Gutemberg Bohórquez sumó un tercero, "el de conceptos típicos de América"45, que le permite definir americanismo como:

la expresión o vocablo español que designa conceptos, bien sea de cosas o actividades culturales, o de objetos exclusivos de América y que forman o han formado parte de la vida del hispanoamericano en su desarrollo cultural, aunque esas voces ya sean patrimonio común del español peninsular, o general, por traslado del objeto o la cosa cultural (p. 105) ${ }^{46}$.

De hecho, ya Rabanales (pp. 26-28) había aludido a las designaciones de objetos naturales o culturales peculiares de países hispanoamericanos, al revisar las definiciones fundadas en el criterio de sinonimia, puesto que estas designaciones son en su mayoría indigenismos que, obviamente, no tienen formas sinónimas en otras modalidades. Este lingüista manifestó su desacuerdo con un fragmento de Juan Valera en el que el escritor español propuso no marcar regionalmente estas voces y sí, en cambio, los "provincialismos o americanismos" de uso restringido, que sí presentan sinónimos ${ }^{47}$. Sin embargo, como se ha visto, ni él ni Rona, tomaron en cuenta esto.

lengua española”, $N R F H, 46,1998,398-401$, con ejemplos de variaciones entre mexicanismos y españolismos).

${ }^{45}$ José Gutemberg Bohórquez, Concepto de "americanismo" en la historia del español. Punto de vista lexicológico y lexicográfico, Instituto Caro y Cuervo, Bogotá, 1984.

${ }^{46}$ BoHórQuez apunta también las posibilidades de clasificación de este conjunto: "vocablos americanos relativos a conceptos de fauna y flora e historia y geografía, y... relativos a los conceptos de las diferentes actividades propias del hispanoamericano en su desarrollo cultural (agricultura, ganadería, organización política, organización económica, etc.)". Y cita autores que en sus repertorios de americanismos han aplicado este criterio: Alcedo, Malaret, Schwauss, Friederici, etc. (ibid., p. 106).

${ }^{47}$ Considero que en su propuesta, Valera manifiesta con claridad que las designaciones de realidades exclusivas de América, por ser únicas y originarias de lenguas indígenas americanas, tenían que pasar a formar parte de la lengua española "oficial" sin indicadores diatópicos, en contraste con los regionalismos con sinónimos, puesto que estos últimos sí requieren de una marca restrictiva que señalara su uso geográfico particular. Copio el fragmento de Valera ofrecido por Rabanales (p. 26), junto con los tres siguientes -todos pertenecientes a la carta "Vocabulario rioplatense razonado" que dirigió Valera a su autor, Daniel de Granada-, donde se advierte que Valera formula su deseo de que la RAE aprovechara ese material: "Será 
José Joaquín Montes Giraldo ${ }^{48}$ replantea la clasificación atendiendo las expuestas por Rabanales y por Rona. Reitera la separación entre americanismos sincrónicos y diacrónicos, a los que denomina, respectivamente, de uso diferencial e históricogenéticos. Identifica, en este segundo grupo, los indigenismos (si proceden de las "lenguas aborígenes americanas"), los africanismos (procedentes de alguna lengua de África, pero oriundos en cualquier región hispanoamericana), los americanismos endohispánicos (originados en Hispanoamérica pero que proceden del español) y los extranjerismos (surgidos de lenguas extranjeras y adoptados en el español americano). Bohórquez -dice- propuso añadir otro grupo: el de las denominaciones de realidades típicas de América -denominaciones que no tienen equivalentes, obviamente, en las demás regiones. Este conjunto, sin

provincialismo o americanismo el vocablo que se emplee sólo en una provincia y que tenga a menudo su equivalente en otras; pero el vocablo que no tiene equivalente y que se emplea en más de una provincia o en más de una república o en regiones muy dilatadas, y más aún cuando designa un objeto natural, que acaso tiene su nombre científico, pero que no tiene otro nombre común o vulgar, este vocablo, digno, siendo muy usual y corriente, es tan legítimo como el más antiguo y castizo, y debe ser incluido y definido en el Diccionario de la lengua castellana. La Academia Española no puede menos de incluirle en su Diccionario. / Así como nosotros, los peninsulares europeos, hemos impuesto a los hispanoamericanos un caudal de voces, que provienen del latín, del teutón, del griego, del árabe y del vascuence, los americanos nos imponen otras voces que provienen de idiomas del Nuevo Mundo y que designan, casi siempre, cosas de por ahí. / Es curiosísimo el catálogo razonado que ha hecho usted de estas voces (de las usadas en la región rioplatense) y las definiciones y explicaciones que da sobre cada una de ellas. Sin duda, su libro de usted será documento justificativo de que los individuos de la Academia Española tengan que valerse y se valgan para aumentar su obra léxica en la edición décimotercera. / Casi todos los vocablos que usted pone y explica en su libro, o no están incluídos (sic) en nuestro Diccionario o están mal o insuficientemente definidos en él. Y sin embargo, no pocos de estos vocablos, a más de estar en poesías, en novelas, en relaciones de viajes y en otras obras en idioma castellano posteriores a la independencia, es casi seguro que se hallan en libros o documentos españoles de antes de la independencia, escritos por los viajeros, misioneros, sabios y demás exploradores de esos países que dieron a conocer en Europa su flora y su fauna" (JuAn VAlera, "Vocabulario rioplatense razonado" [Madrid, 20 de mayo de 1889], en "Cartas americanas", Obras completas, Aguilar, Madrid, 1942, p. 1793).

${ }^{48}$ En su libro Dialectología general e hispanoamericana..., pp. 153-154. También en José JoAQuín Montes Giraldo, Dialectología y geografía lingüistica. Notas de orientación, Instituto Caro y Cuervo, Bogotá, 1970, p. 106, aunque con menos precisión. 
embargo, no convence a Montes por haberse apoyado en un criterio extralingüístico y, además, no necesario, ya que estos americanismos formarían parte de alguno de los grupos anteriores. En cambio, Buesa y Enguita (op. cit., p. 21), lo toman en cuenta como grupo independiente y advierten su presencia en el VPAMER 1789 "y de forma más clara todavía, [en] el Lexicón de fauna y flora de A. Malaret".

Aunque Coseriu no se refiere a un tipo particular de americanismo, al tratar el tema de lo que llama "la región" -que correspondería a las variedades diatópicas de una lengua histórica, como uno de los cuatro tipos de entorno lingüísticodistingue la zona lingüistica y el ámbito objetivo ${ }^{49}$. La primera comprende la extensión dialectal en que se utiliza determinado signo lingüístico -así, por ejemplo, cajuela, en la sincronía actual, pertenecería a la zona lingüistica del español de México, patata a la zona lingüistica de gran parte del español de España y mesa a la zona lingüistica del español general o común. El ámbito objetivo abarca "la región en la que el objeto [en contraste con el signo lingüístico que lo denomina] se conoce como elemento del horizonte vital de los hablantes" ${ }^{50}$-como vieira y acamaya $\mathrm{o}$ charro $^{51}$, que vendrían a ser respectivamente un "españolismo" y dos "mexicanismos" de ámbito objetivo ${ }^{52}$. Precisamente uno de los grupos que tuvo en cuenta Aurora Salvador ${ }^{53}$ fue el de los "americanismos de ámbito objetivo", aclarando que cuando los registró el $D A$ 1726-39 coincidían sus ámbitos objetivos con la zona lingüística del español general:

${ }^{49}$ Cf. E. Coseriu, "Determinación y entorno”, Teoría del lenguaje y lingüistica general. Cinco estudios, $3^{\mathrm{a}}$ ed., Gredos, Madrid, 1973, pp. 311-313 y, de este mismo autor, Principios de semántica estructural, $2^{\mathrm{a}}$ ed., Gredos, Madrid, 1981, pp. 100-107.

${ }^{50}$ E. Coseriu, “Determinación y entorno", p. 311, y Principios de semántica estructural, pp. 100-101.

${ }^{51}$ En el sentido de "Persona dedicada a la cría de ganado siguiendo las tradiciones campiranas mexicanas..." (cf. DEUM).

${ }^{52}$ Transcribo las acepciones correspondientes que ofrece ${ }_{22} D R A E 2001$ : "vieira. (Del gall. vieira). f. Molusco comestible, muy común en los mares de Galicia, cuya concha es la venera, insignia de los peregrinos de Santiago"; "acamaya. (Quizá del nahua) f. Méx. Crustáceo de río parecido al langostino"; "charro (Del eusk. txar, defectuoso, débil)... 5. m. Méx. Jinete o caballista que viste traje especial compuesto de chaqueta corta y pantalón ajustado, camisa blanca y sombrero de ala ancha y alta copa cónica. Ú. t. c. adj.”.

53 "Las localizaciones en el Diccionario de Autoridades", LEA, 7 (1985), 103-139. 
Hay localizaciones geográficas que no corresponden al área idiomática, sino que son externas a ella; se trata de préstamos de lenguas extrañas que designan objetos también extraños, objetos cuyo ámbito objetivo... corresponde a la zona donde se habla esa lengua. Por supuesto, estos vocablos escapan a la intención de este trabajo y he prescindido de ellos... Hemos respetado siempre en casos semejantes, los americanismos, las voces de las Indias Occidentales como el Diccionario las llama, porque en ese caso la coincidencia del ámbito objetivo con lo que ya era zona lingüistica del español las convierte en algo propio y no exótico (ibid., p. 109; las cursivas son mías).

Esta explicación es válida para cacao, chocolate o tomate que ya se habían generalizado en el español, pero no se ajusta a otras voces que incluye el primer repertorio académico. No hay pruebas de que se hubieran generalizado en el español de España y en el de América, y menos aún durante los siglos XVI, XVII y XVIII, vocablos como achichinque, achiote, aguacate 'fruto', calpizque, maguey, ocozoal u ocozol.

Americanismo aparece con dos sentidos en el Diccionario de lingüistica de Fontanillo, justamente los registrados en las dos acepciones del DRAE:

Dícese generalmente del vocablo o rasgo fonético, gramatical o semántico incorporado a una lengua y procedente de las lenguas indígenas americanas desaparecidas o no, como el quechua, el náhuatl, el maya, el araucano, etc.; p. ej. patata, canoa, huracán, cacique. || Desde la perspectiva del español, dícese del vocablo o rasgo fonético, gramatical o semántico, propio de cualquiera de las variedades habladas en Hispanoamérica; p. ej. Vos estás listo, por Tú estás listo, Siempre no vino, por Alfin, no vino.

Lázaro Carreter consigna americanismo en el DTF como: "Palabra de procedencia indígena americana, incorporada a cualquier lengua no americana" y remite a indigenismo, que explica así:

Palabra de procedencia indígena que pasa a una lengua invasora. Se aplica generalmente a voces de lenguas no europeas: indigenismos americanos, africanos, etcétera. Una palabra es indigenismo con relación a la lengua invasora hablada precisamente en el lugar donde vivió o vive la lengua dominada. Petaca, cóndor, chocolate son indigenismos en el español de América. Con relación al español peninsular, son americanismos. 
De hecho, en esta explicación se entrevé una visión eurocéntrica en Lázaro Carreter, pues bastaba con haberse referido a los indigenismos americanos o indoamericanismos que pasaron a formar parte de la lengua española, tanto del español de España como del español de América, es decir, del español general o común, a diferencia, en todo caso, de los indigenismos que se emplean exclusivamente en alguna o varias modalidades del español americano; o sea, distinguir los indigenismos diacrónicos o histórico genéticos de uso general en el mundo hispanohablante, de los indigenismos diacrónicos de uso diferencial.

Reinhold Werner ${ }^{54}$, por su parte, parece no aceptar la existencia de una definición precisa de términos generales como americanismo, ni de los particulares, como pudiera ser el de mexicanismo. Sólo tienen para él "sentido teórico y práctico" los conceptos "histórico-etimológico" y "el sincrónico-diatópico", los que precisa de la siguiente forma:

Primero, un concepto histórico-etimológico, que se basa en el criterio del origen geográfico de los elementos léxicos. Este criterio, aparte de considerar el origen del significante léxico, puede tener en cuenta el origen de las diferentes acepciones o de las diferentes maneras de usar una unidad léxica (por ejemplo, comportamientos gramaticales o colocaciones).

Segundo, un concepto sincrónico-diatópico, que se interesa por elementos específicos del uso lingüístico americano dentro de una sincronía, por ejemplo, la actual. Que sea un elemento específico del español americano o del español de un país o una región de América depende, en este caso, especialmente de cuál es la base de comparación (p. 237).

De esta manera, en el primer diccionario del proyecto "Nuevo diccionario de americanismos" de Haensch y Werner ${ }^{55}$, se aclara que:

no se atiene a ningún criterio genésico (que supondría la incorporación sólo de unidades léxicas originadas en América) ni enciclopédico (que implicaría la inclusión de unidades léxicas

${ }^{54}$ Cf. su artículo: "Principios diferenciales y contrastivos en la lexicografía del español americano", en Encuentro internacional sobre el español de América. Presencia y destino. El español de América hacia el siglo XXI, Instituto Caro y Cuervo, Santafé de Bogotá, 1991, pp. 229-271.

55 Titulado Nuevo diccionario de colombianismos, Instituto Caro y Cuervo, Santafé de Bogotá, 1993. 
con referentes específica o típicamente americanos)... El material léxico que es objeto de descripción se delimita según un criterio diferencial. Se comparan dos variantes nacionales del español, una variante de referencia, el español peninsular, y una variante objeto de tratamiento lexicográfico, el español americano o colombiano, para registrar sólo aquellos elementos de la segunda que no se dan en la primera ("Introducción”, § 1.1, p. xxiii).

\section{Mexicanismo}

Mejicanismo se integró en la nomenclatura de la décimo quinta edición del diccionario académico (1925) como: "Vocablo, giro o modo de hablar propio de los mejicanos" y así se conserva hasta ${ }_{21} D R A E$ 1992. En cambio, mexicanismo se consignó en el "Suplemento" de ${ }_{19} D R A E 1970$, exclusivamente con la remisión al artículo de mejicanismo y la advertencia de la pronunciación particular de su $x^{56}$. Se modificó este orden en la edición más reciente, y así encontramos que bajo mejicanismo aparece sólo la remisión al artículo de mexicanismo, el cual contiene su definición ya sin la advertencia de la pronunciación particular de la $x^{57}$.

La definición académica es semejante a la que resultaría si se aplicase a mexicanismo el razonamiento seguido por Rona (p. 137) para la definición de regionalismo (cf. supra, pp. 523524). De esta forma "todo hecho de lenguaje cuya ocurrencia difiere entre el español mexicano y el del resto de países hispanohablantes" sería un mexicanismo, lo que equivale a lo que Rabanales hubiese designado como mexicanismo stricto sensu. Moreno de Alba se muestra más cauto y realista al aplicar "mexicanismo" a los "vocablos o acepciones que emplea la mayoría

56 "mexicanismo. m. mejicanismo. La $x$ se pronuncia como $j$ ”.

${ }^{57}$ La misma definición que ofrecía en la décimo quinta edición, aunque con la $x$ en el gentilicio: "Vocablo, giro o modo de hablar propio de los mexicanos". No comento ahora nada sobre el atraso del registro de la designación referida a los particularismos de México, pero no puedo dejar de manifestar aquí el rezago de la RAE para admitir la grafía x, especialmente en México, mexicano y mexicanismo, palabras que, incluso más que otras, marcan nuestra identidad. Identidad a la que pareciera que renunció Francisco Santamaría al titular su obra Diccionario de mejicanismos en 1959, en contraste con el título Vocabulario de mexicanismos de la obra inconclusa de Joaquín García Icazbalceta, de 1899. Un interesante artículo sobre las posiciones de diversos historiadores, académicos y escritores ante la $x$ se puede consultar en J.G. Moreno de Alba, "La «X» de México", La lengua española en México, F.C.E., México, 2003, pp. 86-88. 
de los mexicanos y desconoce o emplea poco la mayoría de los no mexicanos" 58 , definición con la que coincido plenamente tratándose del concepto sincrónico-diatópico, aunque para mí es indispensable que la mayoría de los no mexicanos empleen un equivalente del mexicanismo en cuestión.

Evidentemente, definiciones como éstas presuponen la existencia de un "español mexicano", susceptible de ser cuestionado de la misma forma que lo hizo Rona con el "español de América" ${ }^{59}$, impidiendo visualizarlo como una variedad conformada, a su vez, por otras, más o menos generales: yucateca, del altiplano central, juchiteca, norteña, etc.), cuyos contornos no coinciden entre sí -salvo en los casos de fronteras naturalespuesto que sus regionalismos, o micromexicanismos, presentan áreas y límites diferentes, de manera semejante a lo que sucede con los mexicanismos lato sensu, que trascienden las fronteras políticas de México y caracterizan zonas más o menos amplias de Hispanoamérica ${ }^{60}$.

Raúl Ávila coincide con este planteamiento, al señalar que aunque nos limitemos a contrastar dos modalidades, como la del español de España y el español de México, "no se puede tener la certeza de que un fenómeno ocurra en toda la extensión de cada país" ${ }^{61}$ o lo trascienda, como asienta este lingüista después de ofrecer ejemplos léxicos de españolismos y mexicanismos del nivel culto:

Son españolismos desde el punto de vista comparativo en el que me baso ["diferencia connotativa"] palabras como ordenador (DRAE, s.v., $4^{\mathrm{a}}$ acepción), billete (DRAE, acs. 1 a 4; en México sólo se usa la ac. 5: billete de banco), bragas (DRAE, s.v., $1^{\mathrm{a}}$ ac.), jersey (DRAE, s.v., única ac.) o bañador (DRAE, s.v., $3^{\mathrm{a}}$ ac.). Los mexicanismos correspondientes -véase el DEUM- son, respectivamente, computadora, boleto, pantaletas, suéter y traje de baño términos que -de paso-son más generales en el español, con la excepción de nico".

${ }^{58}$ Cf. ibid., pp. 136 y 396, para su concepto de "mexicanismo diacró-

${ }^{59}$ Sigo aquí la observación que hiciera R. Werner (“¿Qué es un diccionario de americanismos?”, en Unidad y variaciones léxicas del español de América, eds. G. Wotjak y K. Zimmermann, Vervuert-Iberoamericana, Frankfurt/M.Madrid, 1994, p. 11) respecto de "la existencia del español argentino o del español colombiano".

${ }^{60}$ Como, por ejemplo, manejar [un vehículo], (teléfono) celular o video que constituyen mexicanismos lato sensu.

61 "Españolismos y mexicanismos”, p. 398. 
pantaletas, cuyo sinónimo más usual en los países hispánicos es calzón(es) (ibid., p. 399; el subrayado es mío).

Reitera, además, que no hay que limitarse a contrastar América con España: "La comparación debería hacerse entre veinte países, y no entre dos regiones" (p. 402).

Sin embargo, se podría postular la existencia del "español de México" con el objetivo práctico de identificar ciertos hechos lingüísticos, los mexicanismos en nuestro caso, y de acuerdo con sus características lingüísticas señalar que los límites de ese español de México coinciden con sus fronteras políticas ${ }^{62}$. Así, parecería posible comparar el español de México con el del resto de las naciones hispanohablantes, en lo que tienen en común y en sus diferencias, tomando en cuenta sus "centros o núcleos" sociolingüísticos por encima de sus periferias, puesto que en éstas se manifiestan las interferencias ${ }^{63}$ y resultan menos transparentes. Por supuesto, esta posible comparación se habría de realizar contrastando niveles de lengua, situaciones de habla y valores expresivos semejantes (culto, coloquial, popular o grosero), para que fuera viable el reconocimiento de los mexicanismos ${ }^{64}$. Pero, sin llevar a cabo este contraste y mientras no se haya registrado lo que es común a todos los dialectos de la lengua, podemos seguir preguntándonos: ¿cómo estar seguros

${ }^{62}$ En los presupuestos formulados para poder llevar a cabo el proyecto del Diccionario del español de México se justificó lingüística y sociolingüísticamente el español de México (cf. Luis Fernando Lara, "Presupuestos generales para el Diccionario del Español de México, M1”, Monografias Generales [documento mecanografiado de trabajos del DEM], 1974, pp 1-5).

63 "Desde el punto de vista de los dialectos, la no coincidencia entre los varios límites dialectales significa sólo que tienen muchas fronteras posibles, o sea, que entre los sistemas dialectales hay interferencias y que entre los dialectos mejor caracterizados suele haber dialectos intermedios o de transición. Y dos dialectos pueden compararse con respecto a lo que tienen en común y a lo que tienen de diferente en sus centros, aunque entre sus límites haya interferencia" (Coseriu, "Los conceptos de 'dialecto'...”, p. 26).

${ }^{64}$ De hecho, los estudios contrastivos más importantes se llevan a cabo considerando la llamada "norma" culta de las ciudades más prestigiosas, que podemos considerar zonas nucleares de las respectivas modalidades, como ocurre con el proyecto del Estudio coordinado de la norma culta de las principales ciudades de Iberoamérica y la Península ibérica. El mismo principio se siguió para la selección de textos dialectales que formarían la lengua no estándar del Corpus del español mexicano contemporáneo 1921-1974 (El Colegio de México, México, 1975), transcribiéndose las cintas grabadas en capitales o ciudades principales de los estados incluidos en cada una de las posibles zonas dialectales, establecidas tentativamente por J.M. Lope Blanch. 
de que un hecho de lenguaje es exclusivo o mayoritario del español de México? ${ }^{65}$.

Desde luego, hemos avanzado e identificado de manera parcial mexicanismos lato sensu -que podría denominar también microamericanismos de México-y en menor proporción, mexicanismos stricto sensu ${ }^{66}$, ambos de uso documentado en la segunda mitad del siglo xx, gracias a los avances alcanzados principalmente en el proyecto Estudio coordinado de la norma lingüistica culta en las principales ciudades de Iberoamérica y la Península ibérica ${ }^{67}$ y en otros trabajos contrastivos ${ }^{68}$.

Por otra parte, la seguridad de calificar un hecho de lengua como mexicanismo, en especial el de uso diferencial, se puede alcanzar a partir de una amplia documentación de textos hispánicos que fuera representativa y que constatara diversos géneros, desde principios del siglo XVI a nuestros días, con precisiones geográficas y temporales, de manera que se pudiera tener presente para cada vocablo su frecuencia de uso y dispersión ${ }^{69}$. Una

${ }^{65}$ Podría pensarse que la pregunta para conocer el tratamiento de los mexicanismos en la trayectoria académica tendría que plantearse de esta manera: ¿cómo han identificado los lexicógrafos los diversos regionalismos, y en particular los mexicanismos, para poder recogerlos en sus obras y presentarlos marcados? Pero, justamente así procedió Rabanales, lo que lo condujo a precisar el concepto de americanismo y de chilenismo ante la falta de coherencia en la selección de estas unidades léxicas, sin que esto, unido a las precisiones posteriores de este concepto, haya coadyuvado a la realización de mejores diccionarios. Reinhold Werner reformula el problema como se entrevé en el título de su artículo: “¿Qué es un diccionario de americanismos?", al asentar que primero hay que detallar el perfil del posible lector del diccionario para caracterizar el diccionario y determinar cómo reunir ese material.

${ }^{66}$ Por ejemplo, las tres voces siguientes: bolero, 'persona que bolea o da grasa a los zapatos'; cajuela, 'lugar destinado a colocar maletas o paquetes grandes, especialmente de un coche o automóvil' y seguro, 'alfiler doblado, cuya punta se encaja en una entrada que impide que se suelte'.

${ }^{67}$ Cf. J.G. Moreno de Alba, Diferencias léxicas entre España y América, Mapfre, Madrid, 1992, pp. 108-162.

${ }^{68}$ Moreno de Alba nos ofrece los resultados de la comparación de las denominaciones de conceptos registrados en cuatro atlas lingüísticos correspondientes básicamente a Andalucía, Canarias y México, y ocasionalmente a Colombia (cf. ibid., pp. 167-194).

${ }^{69}$ Para elaborar un corpus representativo con datos confiables y conocer sus ventajas, se pueden consultar: Luis Fernando Lara y Roberto Ham Chande, "Base estadística del Diccionario del español de México", Investigaciones lingüisticas en lexicografía, El Colegio de México, México, 1979, pp. 7-39 y Roberto Нам Chande, "Del 1 al 100 en lexicografía”, en ibid., pp. 43-83, así como los dos artículos de Luis Fernando Lara, "La cuantificación 
documentación rica se está alcanzando desde finales del siglo xx; en la actualidad se pueden consultar varios corpus, entre ellos, el corpus del español creado por Mark Davies de la Universidad de Brigham Young -compuesto por cien millones de ocurrencias que abarcan desde el siglo XIII hasta fines del xx-y el Banco de datos del español de la RAE con sus dos repertorios, el Corpus diacrónico del español (CORDE) y el Corpus de referencia del español actual (CREA). Como usuaria de las bases de datos de la RAE para confirmar usos de mexicanismos, en épocas muy concretas, puedo hablar de su utilidad, pero tengo dudas sobre su confiabilidad, en especial respecto del cuadro de datos estadísticos por países.

Concluyo este apartado puntualizando mi postura respecto de este término: mexicanismo es el vocablo o la acepción usada mayoritaria o exclusivamente por los mexicanos en contraste con el empleo de equivalentes en el resto de las regiones hispanohablantes, de acuerdo con la perspectiva sincrónica-diatópica o de uso diferencial, así como el vocablo surgido de una de las lenguas prehispánicas de México, se use o no en México, según la perspectiva histórico-genética.

INDICACIONES EN LOS DICCIONARIOS ACADÉMICOS QUE CORRESPONDEN A MEXICANISMOS Y SEUDOMEXICANISMOS

Teniendo en cuenta los tres criterios (histórico-genético, de uso diferencial y de ámbito objetivo) que caracterizan a los mexicanismos y a partir de las ediciones del DRAE en las que se había sistematizado la presentación de los datos etimológicos y de las marcas diatópicas, hay que considerar en ellos las indicaciones siguientes: 1) origen etimológico; 2) marca diatópica o geolectal; 3) notas de uso; 4) información geográfica en la parte correspondiente a la definición:

\section{Origen etimológico}

El grupo de mexicanismos históricos genéticos está constituido prioritariamente por los vocablos provenientes de lenguas indí-

en el Diccionario del español de México" y "Caracterización metódica del Corpus del Diccionario del español de México", Dimensiones de la lexicografía. A propósito del "Diccionario del español de México", El Colegio de México, México, 1990, pp. 51-84 y 85-106, respectivamente. 
genas que se hablan, o se hablaban, en el territorio mexicano: indigenismos mexicanos o indomexicanismos ${ }^{70}$, es decir, nahuatlismos, tarasquismos o purepechismos, mayismos, etc.; este grupo empieza a ser señalizado en las ediciones académicas desde la duodécima ${ }^{71}$, en el paréntesis que sigue a la entrada, con indicación de la lengua de procedencia, la etimología correspondiente o la palabra base de la derivación. Los ilustro con ejemplos de ${ }_{22} D R A E 2001$, en los que destaco por medio del subrayado el tipo de mexicanismos que trato ${ }^{72}$ :

acal. (Del nahua acalli, de atl, agua, y calli, casa). amb. desus. canoa (\| embarcación de remo) (22 DRAE 2003).

Campeche. (De Campeche, ciudad de México) m. V. palo palo de Campeche ${ }_{22}$ DRAE 2003).

chacmol. (Formación mod. del nahua chac mool, [jaguar de] garra roja, [de] garra poderosa). m. En escultura maya, figura de un dios reclinado, con las rodillas dobladas y una vasija sobre el vientre $\left({ }_{22} D R A E 2003\right)$.

chacho ${ }^{2}$, cha. (Quizá del nahua chachacatl.) adj. El Salv. y Hond. Dicho de dos cosas, especialmente de dos frutas: Que están pegadas. || 2. Hond. y Nic. mellizo (||nacido de un mismo parto). || 3. f. pl. El Salv. y Nic. esposas (|| manillas de metal) ( ${ }_{22}$ DRAE 2003).

chancaca. (Del nahua chiancaca, azúcar moreno, o del quechua ch'amqay, triturar). f. Am. Tableta rectangular hecha con la miel que se obtiene de la caña de azúcar $\left({ }_{22} D R A E 2003\right)$.

charal. (Del tarasco charare ). m. Pez teleósteo, fisóstomo, muy comprimido, de unos cinco centímetros de longitud, lleno de espinas, y de color plateado, que se cría con abundancia en las

${ }^{70}$ Similar es la explicación que de ellos hace J.G. Moreno de Alba, La lengua española en México, p. 431: “[Por] mexicanismos diacrónicos... deberán entenderse todos los indigenismos que, procedentes de cualquiera de las lenguas prehispánicas que se hablaban (o se hablan) en lo que hoy es la geografía de México [y que] se han incorporado ya sea al español general (aguacate, chocolate, cacao, tiza, tomate, etc.), ya sea al regional americano (coyote, elote, camote...), ya sea sólo al mexicano (acocote, ayate, cacomiscle, epazote, macehaual [sic], petate, entre cientos de voces más)".

${ }^{71}$ Aclaro que, tanto el $D A 1726-39$ como el ${ }_{2} D A 1770$, muchas veces dan esta información etimológica entremezclada con la definición y otras indicaciones; pero cuando la RAE inicia la publicación de los DRAE elimina, además de las autoridades, dicha información. No será sino hasta ${ }_{12} D R A E$ 1884 cuando se reintroduzcan las etimologías, especialmente para las "voces castellanas".

${ }^{72}$ Ilustro y destaco de la misma forma todos los artículos de acuerdo con el aspecto que se esté tratando. 
lagunas del Estado de Michoacán, en México, y, curado al sol, es artículo de comercio bastante importante. || estar alguien hecho un . fr. coloq. Méx. Estar muy flaco $\left({ }_{22} D R A E 2003\right)$.

chelo $^{2}$, la. (Del maya chel, azul). adj. Méx. Rubio de ojos claros. \| 2. f. fest. coloq. Méx. cerveza ( $\left.{ }_{22} D R A E 2003\right)$.

chihuahua. (De Chihuahua, Estado de México). m. perro chihuahua. || 2. Ecuad. Artificio de fuego que consiste en una armazón de cañas y papelón en figura humana y lleno de pólvora, que se quema en algunas fiestas. || chihuahua. interj. eufem. Méx. Ú. para expresar sorpresa o enfado ( $\left.{ }_{22} D R A E 2003\right)$.

escaupil. (Del nahua ichcatl, algodón, y huipilli, camisa). m. Sayo de armas acolchado con algodón, que usaban los antiguos mexicanos y que los conquistadores adoptaron para defenderse de las flechas $\left({ }_{22} D R A E 2003\right)$.

henequén. (Quizá de or. maya). m. Planta amarilidácea, especie de $\operatorname{pita}^{1}\left({ }_{22}\right.$ DRAE 2003).

tatemar. (Del nahua tlatemati, quemar, poner al fuego $)$. tr. Méx. asar (\| tostar) $\left({ }_{22} D R A E 2003\right)$.

tiza. (Del nahua tizatl. $)$ f. Arcilla terrosa blanca que se usa para escribir en los encerados y, pulverizada, para limpiar metales. || 2. Asta de ciervo calcinada. || 3. Compuesto de yeso y greda que se usa en el juego de billar para frotar la suela de los tacos a fin de que no resbalen al dar en las bolas $\left({ }_{19} D R A E 1970\right.$ ${ }_{22}$ DRAE 2001).

Es de tener en cuenta que hay, además de las voces procedentes de lenguas indígenas, otras formadas a partir del léxico patrimonial de la lengua española y, por lo tanto, son ya nuevas acepciones de voces que habían sido utilizadas con otros significados, como piña, indio, mestizo, oficial real o doctrina, las cuales pudieron constituir, en la perspectiva sincrónica de principios del siglo XVI, americanismos de significado. También se hallan en este grupo nuevas voces derivadas o compuestas de otras patrimoniales, como bezote ${ }^{73}$, cimarrón, vainilla, liquidámbar o palo santo. Se trata de mexicanismos endohispánicos o patrimoniales, cuando se compruebe su uso temprano en México, de acuerdo con la denominación que empleó Montes Giraldo (cf. supra, pp. 530-531).

Los diccionarios no ofrecen ninguna indicación sistemática particular que permita identificar este grupo en los repertorios

${ }^{73}$ Bezote está documentado únicamente en México en los datos de las bases de la RAE (CORDE y CREA), por lo que además de ser mexicanismo endohispánico podría tratarse de un mexicanismo de uso diferencial que ha permanecido como tal hasta el día de hoy, aunque el DRAE no lo ha registrado con la marca correspondiente. 
académicos, aunque en los primeros se precisó, ocasionalmente, que la denominación se debía a los españoles o derivaba de voces de la lengua española, y se explicaba la motivación de su surgimiento; pero, insisto, esto se hizo en muy pocos casos, como en el de armadillo o el de criollo $^{74}$. Sin embargo, si se considera la época desde el descubrimiento hasta el final del virreinato, se puede advertir que este tipo de formación de vocablos se aplicó especialmente para designar plantas, animales y aspectos diversos de la realidad del nuevo mundo -al igual que los indigenismos, que constituyen el conjunto más numeroso- por lo que coincidió con los de ámbito objetivo y de uso diferencial en tanto no se generalizaran, lo cual implicaba otro tipo de indicaciones en los diccionarios, al que me referiré a continuación. Si tomamos en cuenta épocas posteriores a la independencia, se puede decir que los mexicanismos endohispánicos o patrimoniales predominarán sobre los indigenismos en la formación de nuevas voces o de nuevas acepciones ${ }^{75}$, pero los diccionarios sólo los identifican con la marca diatópica correspondiente a México, vaya o no acompañada de otras relativas a otras regiones, o incluida implícitamente en la genérica correspondiente a América, por tratarse de mexicanismos de uso diferencial.

${ }^{74}$ Así: “ARMADILLO. s. m. Animal pequeño en las Indias cubierto de conchas, que cierran, y abren a manera de corazas, por cuya razón le dieron este nombre los españoles. Lat. Animal testudinis speciem referens, \&squamis armatum. ACOST. Hist. Ind. lib. 4. cap. 38. Son unos animalejos pequeños, que andan en montes, y por la defensa que tienen metiéndose entre sus conchas, y desplegándo las como quieren, los llaman armadillos". (DA1726-39) y "CRIOLLO. s. m. El que nace en Indias de padres españoles, o de otras naciones que no sean indios. Es voz inventada de los españoles conquistadores de las Indias y comunicada por ellos en España. Lat. Patria Indus, genere hispanus. ACOST. Hist. Ind. lib. 4. cap. 25. Esta fruta decían algunos criollos (como allá llaman a los nacidos de españoles en Indias) que excedía a todas las frutas de España. OV. Hist. de Chil. pl. 380. Uno de los seis era alemán mestizo de Santiago y criollo, CERV. Viaj. cap. 7. / Descuadernó, desencajó, deshizo / Del opuesto escuadrón catorce hileras, / Dos criollos mató, hirió un mestizo" (DA1726-39).

${ }^{75}$ También es notorio el crecimiento de los mexicanismos histórico genéticos en las últimas décadas que vendrían a calificarse, siguiendo la distinción de Montes Giraldo, como anglicismos dentro del grupo de los extranjerismos (véase supra, p. 530 y Montes Giraldo, Dialectología general e hispanoamericana, p. 153). 
Marca diatópica o geolectal

Para indicar que un vocablo o una acepción se emplea en México (mexicanismo de uso diferencial) ${ }^{76}$, los repertorios académicos usaron la abreviatura Méj. hasta la edición pasada (1992), sustituyéndola por Méx. en la edición más reciente, la que sitúan después de las marcas gramaticales y antes de la definición. Esta marca puede estar acompañada de otras geográficas referidas a países hispanoamericanos y, con menor frecuencia, a alguna región española. También la abreviatura Am. o Amér. puede implicar esta clase de mexicanismos, concretamente, lato sensu. En seguida ofrezco varios ejemplos, la mayoría con la marca restrictiva Méx. en ${ }_{22} D R A E$ 2003:

achiote. (Del nahua achiyotl, de achi-, grano, semilla). m. Am. Cen., Ecuad., Méx., Perú y P. Rico. bija. || 2. m. El Salv. oro (\| metal) ( $\left.{ }_{22} D R A E 2003\right)$.

ahoritita. adv. t. Hond. y Méx. Ahora mismo $\left({ }_{22} D R A E 2003\right)$.

ajolote. (Del nahua axolotl). m. Larva de cierto anfibio urodelo, de unos $30 \mathrm{~cm}$ de longitud, con branquias externas muy largas, cuatro extremidades y cola comprimida lateralmente. Puede conservar durante mucho tiempo la forma larvaria y adquirir la aptitud para reproducirse antes de tomar la forma típica del adulto. Vive en algunos lagos de América del Norte. || 2. Méx. renacuajo (|| larva de la rana) $\left({ }_{22} D R A E 2003\right)$.

atole. (Del nahua atolli, aguado). m. Hond. y Méx. Bebida caliente de harina de maíz disuelta en agua o leche, a la que se pueden agregar sabores edulcorantes. \| dar $\sim$ con el dedo a alguien. fr. Hond. y Méx. Engañarle, embaucarle. $\square$ V. sangre de ( ${ }_{22}$ DRAE 2003).

chaleco. (Quizá del it. giulecco, y este del turco yelek). m. Prenda de vestir sin mangas, que cubre el tronco hasta la cintura y se suele poner encima de la camisa o blusa. 2. m. Jubón de paño de color, cuyas mangas no llegaban más que a los codos, puesto sobre la camisa, escotado, abierto por delante y con ojales y ojetes. Era prenda común entre los turcos. 3. m. And. Mujer despreciable y sin atractivos. Ú. t. c. adj.\| a . loc. adv. Am. Cen. y Méx. por fuerza (\| violentamente) $\left.{ }_{22} D R A E 2003\right)$.

charro, rra. (Del eusk. txar, defectuoso, débil). adj. Aldeano de Salamanca, y especialmente el de la región que comprende Alba, Vitigudino, Ciudad Rodrigo y Ledesma. Ú. t. c. s. ||

${ }^{76}$ Se supone que esta marca diatópica, si no va acompañada de marcas temporales, debería corresponder, cuando menos, al uso temporal cercano al comprendido entre la edición anterior y la edición considerada. 
2. Perteneciente o relativo a estos aldeanos. Traje charro. Habla charra. || 3. Dicho de una cosa: Recargada de adornos, abigarrada o de mal gusto. || 4. Méx. Propio del charro (|| jinete). $\| 5 . \mathrm{m}$. Méx. Jinete o caballista que viste traje especial compuesto de chaqueta corta y pantalón ajustado, camisa blanca y sombrero de ala ancha y alta copa cónica. Ú. t. c. adj. || 6 . f. Hond. Sombrero común, ancho de falda y bajo de copa. \| valer algo charra. fr. Hond. No importar, no recibir la atención que merece ( ${ }_{22}$ DRAE 2003).

chichicuilote. m. Méx. Ave limícola, semejante al zarapito, pero más pequeña, y de color gris, pico largo y delgado. Es comestible y se domestica con facilidad ( $\left.{ }_{22} D R A E 2003\right)$.

chichilasa. f. Méx. p. us. Hormiga de color rojo, pequeña y muy maligna. \|2. Méx. p. us. Mujer hermosa y arisca ${ }_{22} D R A E$ 2003).

chilaquiles. (Del nahua chilli, chile, atl, agua, y quilitl, hierba comestible). m. pl. Méx. Guiso compuesto de tortillas de maíz, despedazadas y cocidas en caldo y salsa de chile $\left({ }_{22} D R A E\right.$ 2003).

chilatole. m. Méx. Guiso de maíz entero, chile y carne de cerdo ( ${ }_{22}$ DRAE 2003).

chilchote. (De chile). m. Méx. Chile muy picante $\left({ }_{22} D R A E 2003\right)$.

chile $^{1}$. (Del nahua chilli). m. Am. Cen. y Méx. pimiento (\| planta herbácea). || 2. Am. Cen. y Méx. pimiento (|| fruto). || 3. coloq. malson. El Salv., Guat. y Méx. pene. || 4. Guat. cuento (|| embuste). Ú. m. en pl. $\| \sim$ ancho. m. Méx. Variedad cuyo fruto es grande, rojo oscuro, y se usa seco. $\| \sim$ chipotle. Méx. chipotle. $\| \sim$ guajillo. Méx. Variedad cuyo fruto es marrón rojizo, largo y estrecho. $\| \sim$ habanero. Méx. Variedad muy picante, en forma de pera de color naranja, que se consume fresco. $\| \sim$ jalapeño. Méx. Variedad cuyo fruto es pequeño, grueso y verde oscuro. || $\sim$ mulato. Méx. chile poblano seco. $\| \sim$ poblano. Méx. Variedad cuyo fruto maduro es largo y de color café oscuro. $\| \sim$ serrano, o verde. Méx. Variedad cuyo fruto es muy picante, pequeño, de color verde y se usa fresco. $\|$ a medios $\sim$ s. loc. adj. Méx. Medio borracho. Ú. t. c. loc. adv. ( $\left.{ }_{22} D R A E 2003\right)$.

chilmole. (Del nahua chilli, chile, y molli o mulli, guiso). m. Méx. Salsa o guisado de chile con tomate $\mathrm{u}$ otra legumbre ${ }_{22} D R A E$ 2003).

chilote $^{1}$. m. Méx. p. us. Bebida que se hace con pulque y chile ( ${ }_{22}$ DRAE 2003).

chinaco. m. despect. Méx. Guerrillero liberal de la época de Maximiliano ( $\left.{ }_{22} D R A E 2003\right)$.

chinchayote. (Del nahua tzintli, lo de abajo, y chayutli, chayote). m. Méx. Raíz comestible del chayote (22DRAE 2003). 
chongo. m. Guat. Rizo de pelo. || 2. Hond. y Méx. Moño de pelo.|| 3. coloq. Perú. escándalo (|| alboroto). || 4. vulg. Perú. prostíbulo. || 5. P. Rico. Caballo malo, ordinario, de poca fuerza. || 6. P. Rico. Racimo de plátanos de calidad inferior. $\| \sim$ s zamoranos. m. pl. Méx. Dulce que se hace de pan frito, o leche cuajada y un almíbar. || agarrarse del . fr. coloq. Méx. Reñir, pelear ( ${ }_{22}$ DRAE 2003).

pulque. (De or. nahua). m. Ecuad. y Méx. Bebida alcohólica, blanca y espesa, del altiplano de México, que se obtiene haciendo fermentar el aguamiel o jugo extraído del maguey con el acocote. $\| \sim$ curado. m. Méx. El que ha sido mezclado con el jugo de alguna fruta $\left({ }_{22} D R A E 2003\right)$.

tilma. (Del nahua tilmatli). f. Méx. Manta de algodón que llevaban los hombres del campo a modo de capa, anudada sobre un hombro ( ${ }_{22}$ DRAE 2003).

tlacuache. (Del nahua tlacuatzin). m. Méx. zarigüeya $\left({ }_{22} D R A E\right.$ 2003).

cuadra. (Del lat. tardío quadra, un cuadrado). f. caballeriza (Il lugar para estancia de caballos y bestias de carga) ... 8 . Espacio de una calle comprendido entre dos esquinas; lado de una manzana... 10. $\underline{A m}$. Medida de longitud, variable según los países, y comprendida más o menos entre los 100 y 150 m... ( ${ }_{22}$ DRAE 2003) ${ }^{77}$.

chequera. f. Cartera para guardar el talonario de cheques. || 2. $\underline{A m}$. Talonario de cheques. || 3. Cuba. Talonario de cupones

${ }^{77}$ La acepción marcada como octava muestra, a partir del su introducción en la duodécima ed., algunas modificaciones, en la caracterización geolectal y en la definición: Cuadra. (Del lat. quadra, cuadro, figura cuadrada). f. Sala o pieza espaciosa. || Caballeriza. || Sala de un cuartel, hospital o prisión, en que duermen muchos. || Cuarta parte de una milla. || Méj. Manzana de casas. || ant. Astron. Cuadratura, $2^{\mathrm{a}}$ acep. || Mar. Ancho por la cuarta parte posterior de la nave. ( $\left.{ }_{12} D R A E 1884\right)$ / Cuadra. (Del lat. quadra, cuadro, figura cuadrada). f. Sala o pieza espaciosa. || Caballeriza. || Sala de un cuartel, hospital o prisión, en que duermen muchos. || Cuarta parte de una milla. \| $\underline{\text { Amér. }}$. Manzana de casas. \|... ( ${ }_{13} D R A E 1899_{{ }_{17}} D R A E$ 1947) / Cuadra... $\|$ 8' bis. Amér. Distancia entre los ángulos de un mismo lado de dicha manzana. $\|\left({ }_{17} D R A E S 1947\right)$ / Cuadra. (Del lat. quadra, cuadro, figura cuadrada). f. Sala... 9. Amér. Manzana de casas. \| 10. Amér. Distancia entre los ángulos de un mismo lado de dicha manzana. || 11... ( $\left.{ }_{18} D R A E 1956,{ }_{19} D R A E 1970\right)$ / Cuadra... 9. [Enmienda]. Amér. Espacio de una calle comprendido entre dos esquinas, lado de una manzana. 10. [Enmienda]. Amér. Medida de longitud, variable según los países, y comprendida más o menos entre los cien y los ciento cincuenta metros $\left.{ }_{19} D R A E \mathbf{S} 1970\right)$ Cuadra... Amér. Espacio de una calle comprendido entre dos esquinas, lado de una manzana. || Amér. Medida de longitud, variable según los países, y comprendida más o menos entre los cien y los ciento cincuenta metros $\left(_{20} D R A E 1984-_{21} D R A E 1992\right)$. 
utilizado para el cobro mensual de jubilados y pensionados. || 4. Cuba. Talonario de recibos que acreditan el pago de determinados servicios $\left({ }_{22}\right.$ DRAE 2003).

tamal. (Del nahua tamalli). m. $\underline{\text { Am }}$. Especie de empanada de masa de harina de maíz, envuelta en hojas de plátano o de la mazorca del maíz, y cocida al vapor o en el horno. Las hay de diversas clases, según el manjar que se pone en su interior y los ingredientes que se le agregan. || 2. $\underline{A m}$. Lío, embrollo, pastel, intriga. || 3. El Salv. y Nic. ladrón (|| persona que hurta o roba) ( ${ }_{22}$ DRAE 2003).

celular. (De célula). adj. Perteneciente o relativo a las células. || 2. Der. Dicho de un establecimiento carcelario: Donde los reclusos están sistemáticamente incomunicados. $\| 3 . \mathrm{m} . \underline{A m}$. teléfono móvil. $\square \mathrm{V}$. coche $\sim$ división $\sim$ furgón $\sim$ gemación $\sim$ membrana $\sim$ pared $\sim$ respiración $\sim$ tejido $\sim$ teléfono $\sim\left({ }_{22} D R A E\right.$ 2003).

Ahora bien, si consideramos que a esta marca corresponden los mexicanismos de uso diferencial que requieren de un sinónimo, tendríamos que excluir de esta lista la primera acepción de atole ('Bebida caliente de harina de maíz disuelta en agua o leche, a la que se pueden agregar sabores edulcorantes'); las dos acepciones de charro, rra presentados con esta marca ('Propio del charro [|ljinete]' y 'Jinete o caballista que viste traje especial compuesto de chaqueta corta y pantalón ajustado, camisa blanca y sombrero de ala ancha y alta copa cónica. Ú. t. c. adj.' ); chichicuilote ('Ave limícola, semejante al zarapito, pero más pequeña, y de color gris, pico largo y delgado. Es comestible y se domestica con facilidad'); la primera acepción de chichilasa ('Hormiga de color rojo, pequeña y muy maligna'); chilaquiles ('Guiso compuesto de tortillas de maíz, despedazadas y cocidas en caldo y salsa de chile'); chilatole ('Guiso de maíz entero, chile y carne de cerdo'); las ocho acepciones de chile, relativas a otras tantas variedades de este fruto (desde $\sim$ ancho a $\sim$ serrano, o verde); chilmole ('Salsa o guisado de chile con tomate u otra legumbre'); chilote $^{1}$ ('Bebida que se hace con pulque y chile'); chinaco ('Guerrillero liberal de la época de Maximiliano'); chinchayote ('Raíz comestible del chayote'); la acepción de chongos zamoranos, bajo chongo ('Dulce que se hace de pan frito, o leche cuajada y un almíbar'); la primera acepción de pulque ('Bebida alcohólica, blanca y espesa, del altiplano de México, que se obtiene haciendo fermentar el aguamiel o jugo extraído del maguey con el acocote') y la referida al pulque 
curado ('El que ha sido mezclado con el jugo de alguna fruta'); tilma ('Manta de algodón que llevaban los hombres del campo a modo de capa, anudada sobre un hombro') y la primera acepción de tamal.

Este grupo de mexicanismos podrían caracterizarse como "mexicanismos de ámbito objetivo", ya que designan implícita o explícitamente ${ }^{78}$ objetos naturales o culturales relativos a México. Esto, aunado a su uso privativo o predominante ${ }^{79}$ en el español de México, respecto de las demás modalidades -excepto la primera acepción de tamal, usada en varias naciones de Centroamérica-, determina también su condición de mexicanismo de uso, y permite distinguir dos clases en este grupo: "mexicanismos de uso diferencial y ámbito objetivo stricto sensu" o, simplemente, "mexicanismos de ámbito objetivo stricto sen$s u$ " -a pesar de no ofrecer en la definición información de la ubicación de ese ámbito ${ }^{80}$, lo que refleja falta de homogeneidad en su tratamiento (cf. infra, pp. 547-553) - y "mexicanismos de uso diferencial y contrastivo stricto sensu" -para aquellos otros que ofrecen sinónimos en otras modalidades. Tamal, por su parte, integraría también el grupo de "mexicanismos de uso diferencial y ámbito objetivo" pero especificado como lato sensu; es decir, "mexicanismos de ámbito objetivo lato sensu".

Por otro lado, creo necesario señalar que un vocablo puede estar caracterizado como mexicanismo con datos etimológicos y con abreviatura de México, o de América, por tratarse de un indomexicanismo de uso diferencial mexicano (stricto sensu) o lato sensu. Y, consecuentemente, los diccionarios académicos informan de las dos características, una en la parte correspondiente a los datos etimológicos y otra con la abreviatura diatópica pertinente, como ocurre con estar alguien hecho un charal, segunda acepción de charal, con las dos acepciones chelo, la, con la interjección eufemística chihuahua y con tatemar, de la sección de origen etimológico (cf. supra, pp. 539-540); así como con las dos de atole, con chilaquiles, chilchote y las acepciones de chile, con chilmole y chinchayote, con las dos de pulque, la de tilma, la de tlacuache y las dos de tamal, todas éstas tomadas de los ejemplos con marca diatópica o geolectal (véase supra, pp. 542-545).

${ }^{78}$ La única acepción en que se manifiesta claramente el ámbito objetivo es la de pulque -"Bebida... del altiplano de México".

${ }^{79}$ Cf. J.G. Moreno de Alba, La lengua española en México, pp. 136 y 396.

${ }^{80}$ Excepto la de pulque, como indico en nota 78. 
Notas de uso

Las marcas que encabezan ciertas acepciones se complementan o matizan con lo que los académicos de la RAE denominan "notas de uso", las cuales presentan al final del texto de la definición. Estas notas pueden referirse a usos gramaticales, precisiones temporales, usos estilísticos o puntualizaciones de nivel de lengua. Algunas de ellas informan sobre el uso mexicano ("en México") o el uso americano ("en América"), identificando de esta forma mexicanismos de uso diferencial stricto sensu y lato sensu:

chapa. (Voz onomat.). f. Hoja o lámina de metal, madera u otra materia. || 2. Tapón metálico que cierra herméticamente las botellas. || 3. placa (|| distintivo de los agentes de Policía). || 4. Entre zapateros, pedazo de piel, comúnmente baldés, con que se aseguran las últimas puntadas en los extremos de las cortaduras o uniones de unas piezas con otras. || 5. Moneda estropeada que se usa como tejo. || 6. Conjunto de las arandelas de la cocina. || 7. Caracol terrestre de gran tamaño, común en Valencia, con la concha deprimida a manera de chapa en su parte superior, aquillada, muy áspera y de color de tierra. || 8. chapeta. || 9. Mancha de color rojo que se ponían artificialmente las mujeres en el rostro. $\| 10$. cerradura (|| mecanismo para cerrar). Ú. m. en América. \|| 11. coloq. Seso, formalidad. Hombre de chapa. || 12. Arg., Cuba y Ur. matrícula (\| placa que llevan los vehículos). || 13. Pan. Dentadura postiza. \| 14. Pan. Persona que vale muy poco. Ese jugador es la chapa. || 15. Perú. Apodo (|| nombre que suele darse a una persona). \| 16. coloq. Ven. Burla, broma festiva, insistente y a veces molesta. || 17. pl. Juego entre dos o más personas, que consiste en tirar por alto dos monedas iguales. Si al caer al suelo quedan ambas con la cara hacia arriba, el que las ha tirado gana a todos y sigue tirando; en caso contrario paga todas las puestas y deja de tirar; y si resulta cara y cruz, ni pierde ni gana, y tira de nuevo. || 18. Juego infantil en que se utilizan las chapas de las botellas. || 19. com. Enfermedad semejante a la sífilis, propia del África occidental. || 20. coloq. Ecuad. Agente de Policía ( ${ }_{22}$ DRAE 2003).

Las notas de uso con información exclusivamente diatópica son escasas; abundan más las que informan de usos gramaticales en una región particular. A continuación ejemplifico varias en las que se pueden observar cuatro acepciones con información 
exclusivamente diatópica y dos (barrial ${ }^{1}$ y regresar) con información gramatical anexada a ella:

aquerenciado, da. (Del part. de aquerenciarse). adj. ant. enamorado. Ú. en México.

barrial $^{1}$. (De $\left.b a r r o{ }^{l}\right)$. adj. ant. Se decía de la tierra gredosa o arcilla. En México y Colombia, ú. c. s. m. || 2. m. barrizal. Ú. m. en América.

disímbolo, la. (De dis ${ }^{1}$ y el gr. $\sigma \dot{u} \mu \beta 0 \lambda o \varsigma$, que se junta con otra cosa). adj. desus. Disímil, diferente, disconforme. Ú. en México.

regresar. (De regreso). tr. Am. Devolver o restituir algo a su poseedor. Regresar un libro. || 2. intr. Volver al lugar de donde se partió. En América, ú. c. prnl.

váguido. m. desus. vaguido. U. en América.

\section{Información geográfica en la parte correspondiente a la definición}

Los diccionarios contienen frecuentemente información, en la sección de la definición, acerca de la ubicación en México o del "ámbito mexicano" de la realidad natural -plantas y animales-, de la realidad sociocultural -alimentos, bebidas, juegos, costumbres, diversiones, etc.- y aun de la "realidad" ficticia o imaginada -creencias generales tradicionalmente establecidas-, denominadas por los vocablos que encabezan los artículos con dichas definiciones. Estas realidades son frecuentemente desconocidas en otras partes, por lo menos en determinado período temporal, y según circunstancias históricas particulares. Justamente estas realidades o "cosas" mexicanas están designadas por vocablos que se podrían reunir en nomenclaturas o terminologías convencionales de México (terminología mexicana jurídicoadministrativa, de la gradación militar, de la flora, la fauna, los enseres domésticos, la gastronomía, etc.), lo cual demuestra que no se trata de información sobre el signo lingüístico. Ahora bien, desde el punto de vista lexicográfico, la indicación del ámbito mexicano o americano -cuando traspasa las fronteras de México sin exceder nuestro continente- de todas estas "realidades" resulta insustituible como parte de la definición, o de la información enciclopédica que se le adjunta, para que el virtual usuario del diccionario pueda hacer una mejor interpretación significativa de la acepción correspondiente ${ }^{81}$. Con base en ello,

${ }^{81}$ Ofrecer las denominaciones de realidades específicas de "ultramar", 
considero que es imprescindible tomar en cuenta estos mexicanismos de ámbito objetivo, stricto y lato sensu, y constatar su tratamiento lexicográfico.

Es importante reconocer que estos mexicanismos con información geográfica en la definición pueden coincidir con los que incluyen datos etimológicos y con los marcados diatópicamente, como había observado Montes Giraldo ${ }^{82}$, y por esto, justamente, los considero "mexicanismos". Así, entre los indomexicanismos ejemplificados antes (véase supra, pp. 539-540), chacmol, charal y escaupil contienen información de ámbito objetivo. Ofrezco a continuación más ejemplos de esta clase, muy numerosa en los repertorios académicos ${ }^{83}$ :

cacle. (Del nahua cactli, zapato o sandalia). m. Sandalia de cuero, usada en México. || 2. coloq. Méx. calzado (|| todo género de zapato) ( ${ }_{22}$ DRAE 2003).

copal.(Del nahua copalli). adj. Se dice de una resina casi incolora, muy dura y sin olor ni sabor, que se emplea en barnices duros

de su fauna y flora, de elementos minerales, de otras materias primas, etc., que habían adquirido importancia debido principalmente a factores económicos, fue la motivación de la elaboración del VPAMER1789 y el criterio implícito de la selección de "voces cubanas" del diccionario de Pichardo. A partir del Nuevo diccionario de la lengua castellana de Vicente Salvá, publicado en 1847, se explicita la necesidad de considerar no sólo estos "americanismos de ámbito objetivo", sino también los "provincialismos": "Es casi total la omisión de las voces que designan las producciones de las Indias orientales y occidentales, y más absoluta la de los provincialismos de sus habitantes; y ninguna razón hay para que nuestros hermanos de ultramar, los que son hijos de españoles, y hablan y cultivan la lengua inmortalizada por tantos poetas e historiadores, no sean llamados a la comunión, digámoslo así, del habla castellana con la misma igualdad que los peninsulares. Si el andaluz, aragonés, extremeño, manchego, murciano, riojano, etc., ven figurar en el Diccionario sus modismos, sus árboles y plantas más comunes, y la nomenclatura más generalizada de sus labores del campo y de sus artes y oficios; es una notoria injusticia que el chileno, filipino, granadino, guatemalteco, habanero, mejicano, peruano, venezolano, etc. no encuentren en él sus provincialismos, los nombres de los frutos del campo que forman su principal sustento, de las plantas y árboles que le son más conocidos, las palabras que emplean en su agricultura y artefactos, y sobre todo en el beneficio de las minas de oro y plata, en que puede decirse que ha sido única hasta poco hace la América, y seguirá probablemente siendo la más rica. Es digno de observarse, que entre las voces introducidas nuevamente en aquellas regiones hay algunas, como dictaminar, editorial y empastar, que convendría se generalizasen en castellano" ("Introducción", p. xiv; las cursivas son mías).

${ }^{82}$ Dialectología general, p. 154.

${ }^{83}$ En todos los ejemplos no destaco las acepciones que, aunque constituyan mexicanismos, no corresponden al grupo que se está ilustrando. 
de buena calidad. Ú. t. c. s. m. || 2. m. Nombre común a varios árboles de la familia de las Burseráceas, de los cuales se extrae la resina del mismo nombre. En México se usa para sahumar templos o casas $\left({ }_{22} D R A E 2003\right)$.

coyote. (Del nahua coyotl, adive). m. Especie de lobo que se cría en México y otros países de América, de color gris amarillento y del tamaño de un perro mastín. || 2. Ecuad., El Salv., Hond. y Méx. Persona que se encarga oficiosamente de hacer trámites, especialmente para los emigrantes que no tienen los papeles en regla, mediante una remuneración $\left({ }_{22} D R A E 2003\right)$.

$\mathbf{c u}^{2}$. (De or. maya). m. En los cronistas de Indias, templo o adoratorio de los indígenas prehispánicos en Mesoamérica ${ }_{22} D R A E$ 2003).

chía $^{2}$. (Del nahua chia o chian). f. Semilla de una especie de salvia. Remojada en agua, suelta gran cantidad de mucilago, que, con azúcar y zumo de limón, es un refresco muy usado en México. Molida, produce un aceite secante $\left({ }_{22} D R A E 2003\right)$.

popote. (Del nahua popotl). m. Paja semejante al bálago, aunque su caña es más corta y el color tira a dorado, usada en México para hacer escobas. || 2. Méx. Pajilla para sorber líquidos ( $\left.{ }_{22} D R A E 2003\right)$.

Ejemplifico también los que contienen abreviaturas geolectales e información de la ubicación del referente en la definición:

agachona. (De agacharse). f. And. chochaperdiz. || 2. Méx. Ave acuática que abunda en las lagunas próximas a la ciudad de México ( $\left.{ }_{22} D R A E 2003\right)$.

bura. m. Méx. Venado del norte de México ( $\left.{ }_{22} D R A E 2003\right)$.

camalote. m. Am. Planta gramínea forrajera acuática o propia de lugares pantanosos. || 2. Arg., Bol., Par. y Ur. Nombre común a varias plantas acuáticas y especialmente a ciertas Pontederiáceas que abundan en las orillas de ríos, arroyos, lagunas, etc. || 3. Arg., Bol. y Ur. Conjunto formado por agregación de estas plantas y otras que arrastra la corriente de los ríos. || 4. Méx. Planta poligonácea acuática que abunda en las costas de México y cuyo tallo contiene una médula, con la cual se hacen flores y figuras para adornar cajas de dulces $\left({ }_{22} D R A E 2003\right)$.

esmedregal. m. Méx. Cierto pez marino del Golfo de México $\left({ }_{22} D R A E 2003\right)$.

pámpano. (Del lat. pampinnus). m. Sarmiento verde, tierno y delgado, o pimpollo de la vid. || 2. pámpana. || 3. salpa (|| pez acantopterigio). || 4. Méx. Pez marino comestible, que habita en las costas del golfo de México ( $\left.{ }_{22} D R A E 2003\right)$. 
saguaro. m. Méx. Planta de la familia de las Cactáceas, que crece en las regiones desérticas de México y el suroeste de los Estados Unidos de América, con flores blancas y fruto comestible ( ${ }_{22}$ DRAE 2003).

trajinera. f. Méx. Embarcación utilizada para transportar carga en los lagos del Valle de México. $\square$ V. punto de $\sim\left({ }_{22} D R A E 2003\right)$.

Los diccionarios académicos también reúnen vocablos que se caracterizan por presentar simultáneamente datos etimológicos, marcas diatópicas e indicaciones geográficas relativas a México en la definición, como se observa en los siguientes ejemplos:

chipilín, na. (Del nahua tzipitl, niño destetado). m. y f. Niño pequeño. || 2. m. El Salv., Guat. y Méx. Planta leguminosa, herbácea, que se mezcla con masa para hacer los llamados tamalitos de chipilín, típicos de Tabasco y Guatemala $\left({ }_{22} D R A E 2003\right)$.

pulque. (De or. nahua). m. Ecuad. y Méx. Bebida alcohólica, blanca y espesa, del altiplano de México, que se obtiene haciendo fermentar el aguamiel o jugo extraído del maguey con el acocote. $\| \sim$ curado. m. Méx. El que ha sido mezclado con el jugo de alguna fruta $\left({ }_{22} D R A E 2003\right)^{84}$.

balché. (Del maya balchê). m. Méx. Árbol del sureste de México, de la familia de las Leguminosas. || 2. Méx. Bebida de fruta fermentada con la cáscara de este árbol $\left.{ }_{22} D R A E 2003\right)$.

ocote $^{1}$. (Del nahua ocotl, tea). m. El Salv., Guat., Hond., Méx. y Nic. Nombre genérico de varias especies de pino americano, aromático y resinoso, nativo desde México a Nicaragua, que mide de 15 a $25 \mathrm{~m}$ de altura ( $\left.{ }_{22} D R A E 2003\right)$.

Estos ejemplos muestran mexicanismos de uso diferencial que no tienen sinónimos en otras regiones, seguramente por no conocerse el objeto al que designan, por lo que podrían especificarse como "mexicanismos genéticos de uso diferencial y ámbito objetivo", al igual que el grupo que deslindé entre los que únicamente presentan marca diatópica (véase supra, pp. 542-545), y sólo se distinguen de éstos en la información explícita del ámbito objetivo.

Hay también, en los repertorios académicos, artículos con otras informaciones geográficas referidas a México en la defini-

${ }^{84}$ La segunda acepción también constituye un mexicanismo de ámbito objetivo, lo mismo que la segunda de balché, aunque en ambos casos éste está implícito por la referencia a la primera acepción. 
ción que no ofrecen datos etimológicos ni marcas geográficas restrictivas, o bien, con datos etimológicos que no corresponden a lenguas indígenas mexicanas. Veamos los siguientes:

adoratorio. $\mathrm{m}$. Templo en que los indios americanos daban culto a algún ídolo. || 2. Retablillo portátil para viaje o campaña ( ${ }_{15}$ DRAE 1925- ${ }_{22}$ DRAE 2001).

aguascalentense. adj. Natural de Aguascalientes. Ú. t. c. s. || 2. Perteneciente o relativo a esta ciudad o a este Estado de México ( ${ }_{22}$ DRAE 2003).

alcalde... $\| \sim$ mayor $m$. Juez de letras que ejercía la jurisdicción ordinaria en algún pueblo. || 2. Juez de letras, asesor del corregidor en las ciudades donde este era juez lego. || 3. En el virreinato de Nueva España, el que, siendo o no juez de letras, gobernaba por el rey algún pueblo que no era capital de provincia. || 4. En las antiguas provincias de Ultramar, juez de primera instancia que, además de las atribuciones propias de este cargo, ejercía otras gubernativas, administrativas y económicas $\left({ }_{22} D R A E 2003\right)$.

angelopolitano, na. (Der. culto de Puebla de los Ángeles, nombre original de la ciudad de Puebla). adj. Natural de Puebla. Ú. t. c. s. || 2. Perteneciente o relativo a esta ciudad, capital del Estado de Puebla, en México $\left({ }_{22} D R A E 2001\right)$.

bezote. (De bezo) $\mathrm{m}$. Adorno o arracada que usaban los indios de América en el labio inferior ( $\left.{ }_{15} D R A E 1925-{ }_{22} D R A E 2001\right)$.

caimán. (Del taíno kaimán). m. Reptil del orden de los Emidosaurios, propio de los ríos de América, muy parecido al cocodrilo, pero algo más pequeño, con el hocico obtuso y las membranas de los pies muy poco extensas. || 2. Persona que con astucia y disimulo procura salir con sus intentos $\left({ }_{22} D R A E 2001\right)$.

cristero, ra. adj. Se dice de quienes, al grito de "¡Viva Cristo Rey!”, en México, se rebelaban, por los años 1926 a 1929, durante el conflicto entre la Iglesia y el Estado. Ú. t. c. s. $\left({ }_{22} D R A E 2003\right)$.

chaparreras. f. pl. Especie de zahones de piel adobada que se usan en México.

chayotera. f. Planta trepadora americana, de la familia de las Cucurbitáceas, de tallo liso, delgado y muy resistente, hojas acorazonadas divididas en tres lóbulos, flores pequeñas, acampanadas, de color blanco con ligeras tonalidades verdosas. $\mathrm{Su}$ fruto es el chayote $\left({ }_{22} D R A E 2001\right)$.

chetumalense. adj. Natural de Chetumal. Ú. t. c. s. || 2. Perteneciente o relativo a esta ciudad, capital del Estado de Quintana Roo, en México ( ${ }_{22}$ DRAE 2003).

chicha $^{2}$. (De la voz aborigen del Panamá chichab, maíz). f. Bebida alcohólica que resulta de la fermentación del maíz en agua 
azucarada, y que se usa en algunos países de América. || 2. Chile. Bebida que se obtiene de la fermentación del zumo de la uva o de la manzana. || 3. Cuba. Bebida refrescante preparada con azúcar y cáscaras de piña fresca que se han dejado fermentar en agua dos o tres días. || 4. Pan. Refresco hecho con frutas. || 5. Perú. Ú. en aposición para referirse a cualquier manifestación cultural de origen occidental interpretada y desarrollada por inmigrantes andinos en ciudades grandes como Lima. Cultura chicha, música chicha. \| 6. Perú. Ú. en aposición para referirse a toda actividad informal, de mal gusto y de baja calidad. || 7. Ven. Bebida refrescante hecha con arroz, leche y especias $\left({ }_{22} D R A E 2003\right)$.

taco. m... || 10. m. Tortilla de maíz enrollada con algún alimento dentro, típica de México... ( $\left.{ }_{22} D R A E 2003\right)$.

tiradera.(De tirar). f. Flecha muy larga, de bejuco y con punta de asta de ciervo, usada por los indios de América, que la disparaban por medio de correas. || 2. rur. Ar. Clavo grande de hierro con una cadena para arrastrar maderos $\left({ }_{19} D R A E\right.$ $\left.1970-{ }_{22} D R A E 2003\right)$.

totoloque. m. En los cronistas de Indias, juego de los antiguos mexicanos, parecido al tejo $\left({ }_{22} D R A E 2003\right)$.

zapatismo. m. Movimiento agrarista revolucionario, que lideró Emiliano Zapata en México a principios del siglo xx. || 2. Movimiento surgido con el levantamiento campesino del Estado mexicano de Chiapas en 1994, que reivindica los postulados del zapatismo $\left({ }_{22} D R A E 2003\right)$.

Se podría decir que, en estos casos, los señalamientos al ámbito objetivo de México, sin referencia a ninguna otra cualidad que posibilite su identificación como mexicanismos, permiten suponer que se trata en realidad de hechos de la lengua general española y, por consiguiente no deberían de formar parte de de este trabajo. Sin embargo, la revisión de las distintas ediciones me permitió advertir ciertas particularidades en su tratamiento lexicográfico, como la falta de indicaciones etimológicas $^{85}$ (observadas en derivados de indigenismos, como en chayotera $^{86}$, chetumalense y, probablemente, en totoloque ${ }^{87}$ )

${ }^{85}$ Justificadas en algunos casos por las normas, implícitas o explícitas, vigentes en las distintas ediciones.

${ }^{86}$ La falta de datos etimológicos y marca diatópica aquí puede deberse a la mención de chayote en su definición, y a que éste ofrece información etimológica en su propio artículo.

${ }^{87}$ Aunque esta denominación se atribuye a Bernal Díaz del Castillo (cf. este artículo en Cecilio Agustín Robelo, Diccionario de aztequismos, y en 
o de marcas diatópicas (chaparreras, chayotera), que no explicitan su cualidad de indomexicanismos o de mexicanismos de uso diferencial.

Otros casos responden al hecho de haberse generalizado lo que en determinado lapso constituyó un mexicanismo de uso diferencial y ámbito objetivo (chicha ${ }^{88}$, taco, zapatismo) -o un antiguo regionalismo de otro territorio americano que se extendió en Hispanoamérica (agutí, caimán ${ }^{89}$ )-, debido a la propagación de la realidad a la que aludía, grupo en el que podemos incluir las palabras históricas -cuyo ámbito objetivo, además de estar limitado a México, o a América, corresponde a realidades más o menos lejanas en el tiempo-, como adoratorio, alcalde mayor, bezote, cristero, tiradera, totoloque, y las dos acepciones de zapatismo en cuyas definiciones se precisan también los datos cronológicos de la vigencia de la realidad designada en la definición, o los puede inferir el lector a partir de los tiempos verbales en pasado empleados en ella y de otras precisiones relativas al contexto situacional ${ }^{90}$. En circunstancias similares a éstas se hallan los gentilicios de procedencia no indígena (aguascalentense; angelopolitano, na), en los que la información del ámbito en la definición es indispensable. No obstante, el conocimiento activo, y aun el disponible o pasivo, de los vocablos que habiendo sido mexicanismos de ámbito objetivo ya se generalizaron, de los históricos y de los gentilicios de significante patrimonial depende más del conocimiento histórico, geográfico o de diversas áreas terminológicas de todos los hispanohablantes que del de un grupo circunscrito a una región determinada. Por ello, al igual que los diccionarios de

Francisco Javier Santamaría, Diccionario de mejicanismos), podría interpretarse como un indomexicanismo.

${ }^{88}$ Chicha constituye, según Luis Cabrera (Diccionario de aztequismos), un mexicanismo histórico genético, que se difundió rápidamente en Hispanoamérica, por lo que pasó a ser un mexicanismo de ámbito objetivo lato sensu.

${ }^{89}$ Parece ser que este vocablo y el conocimiento del animal tuvieron una propagación muy rápida durante el siglo xvi, llegando a España, como lo constata el Tesoro de Covarrubias. Considero que su difusión en ese país fue a partir de lo especificado por Fernández de Oviedo en 1540 acerca de que "se traga a los hombres enteros", como lo detalla Covarrubias. Fue también seleccionado por RAfael LAPESA en su Historia de la lengua española ( $9^{\mathrm{a}} \mathrm{ed}$,, Gredos, Madrid, 1999, p. 557) entre los americanismos de gran difusión geográfica.

${ }^{90}$ Por ejemplo, la indicación "En los cronistas de Indias", ofrecida al principio de la definición de totoloque. 
la RAE, que no los marcan, no los considero mexicanismos, sino "pseudomexicanismos" 91 , pero que lo mismo que los mexicanismos de ámbito objetivo, tienen que explicitar el ámbito del referente en la definición. Es decir, los vocablos que denominan realidades exclusivas o peculiaridades de México y, por lo tanto, de uso mayoritario o exclusivo de los mexicanos, pero que no pueden contrastarse con un equivalente en las demás regiones hispanohablantes, puesto que en ellas no se conoce ni forma parte de su cultura "la cosa" u "objeto" designado por ellos, no constituyen mexicanismos sino pseudomexicanismos, a menos que cumplan con el criterio histórico-etimológico. De esta forma, constituyen pseudomexicanismos las acepciones siguientes: la de tortilla que designa la "porción de masa de maíz prensada o hecha a mano en forma circular de $15 \mathrm{~cm}$ aproximadamente, fundamental en la alimentación y la cocina mexicana" ${ }^{92}$, la acepción de taco correspondiente a: "tortilla de maíz o de harina enrollada y generalmente rellena de algo, como frijoles, salsa, carne, etc" ${ }^{93}$ y la de chaparreras ${ }^{94}$.

Un conjunto problemático en los diccionarios de lengua lo constituyen los derivados de nombres propios, justamente porque los diccionarios se caracterizan por excluir los nombres propios de sus nomenclaturas, por lo que éste, incluido en la definición como definiente insustituible, tiene que estar caracterizado sucintamente para aclarar las dudas del virtual consultor de la obra. En consecuencia, en las definiciones de adjetivos y sustantivos deonomásticos de lugar -gentilicios y vocablos que identifican a grupos indígenas o las lenguas que éstos hablan- y en las definiciones de derivados deonomásticos de persona, se requiere obligatoriamente de este tipo de precisiones enciclopédicas.

Al tomar en cuenta los pseudomexicanismos y distinguirlos de los mexicanismos propiamente dichos, se detectan interferencias en el tratamiento de ambos grupos, que reflejan falta de homogeneidad en su presentación. De esta manera advertí

${ }^{91}$ Los diccionarios diferenciales de americanismos de la primera mitad del siglo xx, lo mismo que los diferenciales de mexicanismos, consignan este tipo de vocablos.

${ }^{92}$ Cf. tortilla en LARA et al., Diccionario del español usual en México, El Colegio de México, México, 1996. Aclaro que esta acepción sería un pseudomexicanismo lato sensu, ya que se emplea también en parte de América Central, en Puerto Rico y en la República Dominicana, según el DRAE.

${ }^{93}$ Cf. L.F. LARA et al., op. cit.

${ }^{94}$ Cf. estos artículos en supra, pp. 552-553. 
que, en las últimas ediciones, se aplica el tratamiento de los pseudomexicanismos a un grupo de vocablos caracterizados por su poco uso, por la restricción de su ámbito objetivo o por la limitación temporal de su aplicación:

chalupa. (Del fr. chaloupe, y este del neerl. sloep). f. Embarcación pequeña, que suele tener cubierta y dos palos para velas. || 2. lancha (|| embarcación que llevan a bordo los grandes buques). || 3. En las chinampas de México, canoa o embarcación de diferentes formas y para distintos usos. || 4. Méx. Tortilla de maíz gruesa, pequeña y ovalada, con algún condimento por encima ( $\left.{ }_{22} D R A E 2003\right)$.

chiqueadores. m. pl. Rodajas de carey que se usaron antiguamente en México como adorno femenino. || 2. Méx. Rodajas de papel, como de una pulgada de diámetro, que, untadas de sebo u otra sustancia, se pegan en las sienes como remedio casero para los dolores de cabeza $\left({ }_{22} D R A E 2003\right)$.

ante $^{2}$. (Del lat. ante) . prep. frente a (\| enfrente de). || 2. En presencia de. || 3. En comparación, respecto de. || 4. adv. t. ant. antes (\| con idea de prioridad de tiempo). $\| 5 . \mathrm{m}$. Plato o principio con que se empezaba la comida o cena. || 6. p. us. Postre que se hace en México, de bizcocho mezclado con dulce de huevo, coco, almendra, etc. \|... ( $\left.{ }_{22} D R A E 2003\right)$.

Si se contrastan estas acepciones con otras semejantes, como por ejemplo: la sexta acepción de ante $^{2}$ con la de la primera de chichilasa, marcada como mexicanismo y sin referencia de ámbito ("chichilasa. f. Méx. p. us. Hormiga de color rojo, pequeña y muy maligna...", cf., supra, p. 543), destaca la falta de tratamiento uniforme, ya que lo que a simple vista las distingue es la presencia de referencia al ámbito en una y la marca geolectal en otra, lo que aunado a la definición permite su interpretación como pseudomexicanismos. Las dos voces son efectivamente de poco uso, ante se empleaba con poca frecuencia a finales del siglo XIX ${ }^{95} \mathrm{y}$ chichilasa tiene testimonio de Moreno de Alba como voz prácticamente desconocida en nuestro país ${ }^{96}$, que efectiva-

${ }^{95}$ Esta acepción se la debemos a JoAQuín García Icazbalceta (Vocabulario de mexicanismos de 1899, s.v.), quien la introdujo con la advertencia de "poco se usa ya". La RAE la introdujo en la ed. décima quinta de 1925 tal y como aparece en ${ }_{22}$ DRAE 2001.

${ }^{96}$ Cf. J.G. Moreno de Alba, Minucias del lenguaje, Océano, México, 1987, p. 114, quien hace estos señalamientos con respecto al ${ }_{20} D R A E 1984$. De hecho este artículo fue introducido en ${ }_{16} D R A E 1936$, y no ha tenido enmiendas, salvo la modificación ortográfica de la abreviatura geolectal. 
mente es mexicanismo, pero no por su poco uso en México, sino por ser histórico genético, ya que se trata de un nahuatlismo formado a partir de chichiltic 'cosa colorada' y ázcatl 'hormiga', información que no incluye el DRAE. Si se decide mantener estas dos voces, sería preferible presentarlas en forma semejante y con ciertas precisiones, que podría proponer como: "ante... m. p. u. Postre que se hacía en México, de bizcocho mezclado con dulce de huevo, coco, almendra, etc. u. ant. en México" y “chichilasa (chichiltic 'cosa colorada' y ázcatl 'hormiga') f. p. us. Hormiga de color rojo, pequeña y muy maligna, que abunda en México".

Por otra parte, las precisiones de ámbito en la definición de pseudomexicanismos también son exigidas en vocablos derivados de nombres propios, ya de lugares, como ocurre con los gentilicios, ya los que identifican a grupos indígenas o a las lenguas que estos hablan. Ejemplifico este conjunto ${ }^{97}$ :

abajeño, ña. (De abajo). adj. Natural de El Bajío. Ú. t. c. s. || 2. Perteneciente o relativo a esta región de los Estados de Guanajuato, Michoacán y Jalisco, en México. || 3. Am. Natural o procedente de costas y tierras bajas. Ú. t. c. s. || 4. rur. Arg. sureño $\left({ }_{22} D R A E 2003\right)$.

defeño, ña. (Del deletreo de la sigla D. F., Distrito Federal). adj. Natural de la ciudad de México o del Distrito Federal. Ú. t. c. s. || 2. Perteneciente o relativo a esta ciudad, capital de México ( ${ }_{22}$ DRAE 2003).

jarocho, cha. (Cf. farota). adj... || 2. Natural de Veracruz, ciudad de México. Ú. t. c. s. $\left({ }_{22} D R A E 2003\right)^{98}$.

${ }^{97}$ Selecciono ejemplos que no tienen datos etimológicos ni marcas diatópicas, a diferencia de los dos siguientes: "acapaneca. (Del nahua Acapan, sobre las cañas y-ecatl, morador de). adj. Se dice del individuo de un pueblo amerindio del Estado mexicano de Jalisco. Ú. t. c. s. || 2. Perteneciente o relativo a los acapanecas" ( $\left.{ }_{22} D R A E 2003\right)$ // "chichimeco, ca. (Del nahua chichimecatl). adj. Se dice del individuo de una tribu que se estableció en Tezcuco y, mezclada con otras que habitaban el territorio mexicano, fundó el reino de Acolhuacán. MORF. Ú. m., para referirse al masculino, la forma chichimeca. Ú. m. c. s. pl. Los chichimecas. || 2. Se dice de los indios que habitaban al poniente y norte de México. MORF. Ú. m., para referirse al masculino, la forma chichimeca. Ú. m. c. s. pl. || 3. Perteneciente o relativo a los chichimecos. MORF. Ú. m., para referirse al masculino, la forma chichimeca. El origen chichimeca" ( ${ }_{22}$ DRAE 2003).

${ }^{98}$ En este artículo, llama la atención "ciudad de México" puesto que para los mexicanos ésta es por antonomasia la capital del país, por lo que sería más preciso referirse a la "ciudad del estado con el mismo nombre, de México", o mejor: "ciudad y puerto del estado de Veracruz, en México". Lo mismo 
otumbeño, ña. adj. Natural de Otumba. Ú. t. c. s. || 2. Perteneciente o relativo a este municipio del Estado mexicano de México $\left({ }_{22}\right.$ DRAE 2003) ${ }^{99}$.

regiomontano, na. adj. Natural de Monterrey, ciudad de México, capital del Estado de Nuevo León. Ú. t. c. s. || 2. Natural de Königsberg, ciudad de la antigua Prusia oriental. Ú. t. c. s. \| 3 . Perteneciente o relativo a alguna de estas ciudades $\left({ }_{22} D R A E\right.$ 2003).

tapatío, a. adj. Natural de Guadalajara. Ú. t. c. s. || 2. Perteneciente o relativo a este Estado de México o a su capital. $\square$ V. jarabe $\sim\left({ }_{22}\right.$ DRAE 2003) ${ }^{100}$.

veracruzano, na. adj. Natural de Veracruz. Ú. t. c. s. || 2. Perteneciente o relativo a este Estado o ciudad de México $\left({ }_{22} D R A E\right.$ 2003).

mazateco $^{1}$, ca. adj. Se dice del grupo indígena que habita en el Estado mexicano de Oaxaca, en la zona limítrofe con Guerrero y Puebla. Ú. t. c. s. || 2. m. Lengua que habla dicho grupo indígena ( $\left.{ }_{22} D R A E 2003\right)$.

totonaco, ca. adj. Se dice de una gran tribu de México, que habita hacia la costa del golfo. $\| 2$. Perteneciente o relativo a este pueblo. || 3. m. Lengua del mismo ( $\left.{ }_{22} D R A E 2003\right)$.

zoque.1. adj. Se dice de un grupo indígena mexicano que habita los Estados de Chiapas, Oaxaca y Tabasco. Ú. t. c. s. || 2. Perteneciente o relativo a este grupo indígena. || $3 . \mathrm{m}$. Lengua hablada por dicho grupo ( $\left.{ }_{22} D R A E 2003\right)$.

En este mismo grupo de derivados, aunque en menor número, se hallan además los referidos a personas, o sea, los adjetivos y sustantivos deonomásticos de persona, los cuales requieren a veces precisiones enciclopédicas sobre la nacionalidad de los personajes ${ }^{101}$ o la ubicación de algún hecho

sucede en la información etimológica de Campeche (supra, p. 539) y en diversos gentilicios, como regiomontano o veracruzano.

${ }^{99}$ Supongo que Otumba es un indigenismo, aunque el diccionario académico no da datos que así lo indiquen. Más segura estoy de los tres últimos ejemplos (mazateco, totonaco y zoque) en los que no se da información etimológica. Sería conveniente explicitar su procedencia con la mención del nombre propio cuando se requiera, como se hizo con acapaneca (véase supra, n. 97).

${ }^{100}$ La mayúscula de "Estado" en las definiciones de varios gentilicios correspondientes a México desorienta, al menos, a los lectores mexicanos contemporáneos acostumbrados a distinguir el Estado de México del resto de "los estados de México".

${ }^{101}$ Ofrezco el artículo de acantinflado, presentado como mexicanismo de uso diferencial y ámbito objetivo lato sensu: "acantinflado, da. adj. Bol., Chile, 
sociohistórico importante en el contexto cultural mexicano, como ameritaron, por ejemplo, cristero o zapatismo (véase supra, pp. 552-553) ${ }^{102}$.

Los pseudomexicanismos son un grupo problemático principalmente para los diccionarios diferenciales de mexicanismos que, sin un criterio claro, incluyen algunas de estas voces en sus nomenclaturas. Es necesario insistir en que los pseudomexicanismos conformados por gentilicios o por designaciones de grupos indígenas, así como las palabras históricas o los deonomásticos referidos a personas, no se justifican en un diccionario diferencial de mexicanismos, ni de americanismos ${ }^{103}$. Este tipo de obras debería incluir exclusivamente aquellos derivados deonomásticos que constituyen mexicanismos histórico genéticos, mexicanismos de uso diferencial y mexicanismos ámbito objetivo. Y, al contrario, en los diccionarios integrales -generales del español o nacionales de México-sí se justifica su presencia, en especial la de gentilicios que contengan matices eufemísticos, afectivos o despectivos (chicano) y los que no deriven regularmente del nombre de un lugar (jarocho, gentilicio referido al puerto de Veracruz; tapatio, el correspondiente a la ciudad de

Méx. y Ven. Que habla a la manera peculiar del actor mexicano Cantinflas" ( $\left.{ }_{22} D R A E 2003\right)$. En cambio, este mismo repertorio ofrece cantinflesco, cantinflear, así como cantinflada, cantinfleo y cantinflero sin ninguna nota en la definición que permitiera suponerlos relacionados con la forma de expresarse del actor mexicano Cantinflas. Posiblemente los redactores de la última versión del diccionario académico, cumpliendo con la norma de no incluir datos de procedencia en los derivados cuando la palabra base constituye un definiente, supusieron que bastaría con lo expuesto bajo cantinflas: "(De Cantinflas, popular actor mexicano.) m. Méx. Persona que habla o actúa como Cantinflas", para no repetir la información, olvidando que los usuarios de diccionarios hacen generalmente consultas muy puntuales.

${ }^{102}$ A este grupo pertenecen también porfirismo, porfirista, porfiriato, maderismo, vocablos no incluidos aún en el diccionario académico. La última ed. ofrece maderista, pero no con el sentido que tiene para los mexicanos ("maderista adj. y s. m. y f. Que es partidario del maderismo o se relaciona con este movimiento político: las fuerzas maderistas, "Los maderistas tomaron Ciudad Juárez»", DEUM); sino como aragonesismo: "maderista. m. Ar. maderero (\| conductor de maderadas)" ( ${ }_{22}$ DRAE 2003).

${ }^{103}$ GÜnNTher Haensch y Reinhold Werner ("Un nuevo diccionario de americanismos: proyecto de la universidad de Augsburgo", BICC, 33, 1978, 375-384) revisaron la "inclusión de nombres de naciones y tribus indígenas" -la mayoría indigenismos- en varios diccionarios diferenciales, y señalaron que en ellos "aparecen numerosos nombres de naciones y tribus indias, sin que la enumeración de éstas sea completa”, y añaden: "Sería más conveniente reunir todos estos nombres en un diccionario etnológico de uso" (p. 37). 
Guadalajara), siempre y cuando se constate el uso real de esos gentilicios, y no sus posibilidades de uso ${ }^{104}$.

Hay que tener en cuenta que los adjetivos deonomásticos de personas se forman -o se formaron- mediante un número reducido de sufijos de elevada productividad (-iano/a, -ano/a, -esco/a, -ino/a, -ista $)^{105}$ que permiten deducir el significado de los vocablos por ellos conformados. En situación similar se encuentran los gentilicios, constituidos especialmente por seis sufijos de cierta productividad en la lengua común (-ano/a, -nse, -eño/a, -és/a, -í,-iano/a), a los que habría que añadir el sufijo -eco, de procedencia náhuatl, que únicamente se anexa a bases de origen también indígena.

Respecto de los diccionarios generales del español, en concreto de los DRAE, se puede decir que abundan los gentilicios en sus nomenclaturas, incluso los de localidades pequeñas, sean mexicanismos o pseudomexicanismos ${ }^{106}$. Pero, en cambio, se advierte la falta de derivados antroponomásticos que no pertenecen al ámbito sociohistórico cultural de España, entre los que predominan los que integran el grupo de pseudomexicanismos. En ${ }_{22} D R A E 2001$, por ejemplo, están consignados barojiano, na; cervantino, na; machadiano, na (de Antonio Machado) y unamuniano, na, pero no, rulfiano, na (de Juan Rulfo); también se hallan franquismo y franquista, pero no porfiriano, na; porfiriato ni porfirista, y sí, en cambio, zapatismo y zapatista, sin que se haya explicado qué criterio subyace a este tratamiento y, supongo, sin haber cuestionado si el lugar de este sector léxico debe integrar la nomenclatura de un diccionario general de la lengua española o podría ofrecerse en tablas o cuadros en apéndices específicos.

Con la finalidad de tener una visión más clara del tratamiento lexicográfico de los regionalismos, así como de las voces con

${ }^{104}$ Es el caso de la presencia en ${ }_{22} D R A E 2001$ del gentilicio mexiqueño, ña que nadie usa: "mexiqueño, ña. adj. Natural de México. Ú. t. c. s. || 2. Perteneciente o relativo a esta ciudad, capital de la República Mexicana". Posiblemente se incluyó en ese repertorio por haberlo seleccionado la Academia Mexicana, ya que lo consigna en el Diccionario breve de mexicanismos de Guido Gómez de Silva.

105 Cf. RAE, Gramática descriptiva de la lengua española, Espasa, Madrid, 1999, t. 3, pp. 4621-4622.

${ }^{106}$ Así: cholulteco, ca; mazatleco, ca; otumbeño, ña u otompaneco, ca; sancristobaleño, ña; taxqueño, ña; tepozteco, ca; tezcucano, na; tierracalenteño, na o tierracalentano, na, todos ellos consignados en la última ed. (2001). 
precisiones geográficas en la parte de la definición, reconocidas o no como tales, he revisado aquí las aportaciones de la tradición lexicográfica española y de varios lingüistas sobre el concepto de dialectalismo, particularmente de mexicanismo, para distinguirlo del de pseudomexicanismo, y he descrito su identificación en el diccionario académico. Este trabajo queda como preliminar para el estudio pormenorizado del tratamiento de los mexicanismos en la historia de la trayectoria diccionarística de la RAE.

Luz FernÁNDEZ GoRdillo

El Colegio de México 
